\title{
Simulation study of dynamic aperture with head-on beam-beam compensation in the RHIC
}

\author{
Y. Luo, W. Fischer
}

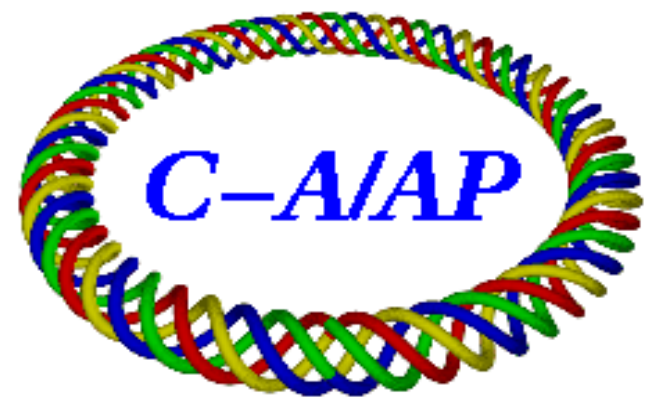

\section{Collider-Accelerator Department Brookhaven National Laboratory \\ Upton, NY 11973}

Notice: This document has been authorized by employees of Brookhaven Science Associates, LLC under Contract No. DE-AC02-98CH10886 with the U.S. Department of Energy. The United States Government retains a nonexclusive, paid-up, irrevocable, world-wide license to publish or reproduce the published form of this document, or allow others to do so, for United States Government purposes. 
April 1, 2010

\title{
Simulation study of dynamic aperture with head-on beam-beam compensation in the RHIC
}

\author{
Y.Luo, W. Fischer \\ Brookhaven National Laboratory, Upton, NY 11973, USA
}

In this note we summarize the calculated $10^{6}$ turn dynamic apertures with the proposed head-on beambeam compensation in the Relativistic Heavy Ion Collider (RHIC). To compensate the head-on beam-beam effect in the RHIC $250 \mathrm{GeV}$ polarized proton run, we are planning to introduce a DC electron beam with the same transverse profile as the proton beam to collide with the proton beam $[1,2]$. Such a device to provide the electron beam is called an electron lens (e-lens). In this note we first present the optics and beam parameters and the tracking setup. Then we compare the calculated dynamic apertures without and with head-on beam-beam compensation. The effects of adjusted phase advances between IP8 and the center of e-lens and second order chromaticity correction are checked. In the end we will scan the proton and electron beam parameters with head-on beam-beam compensation.

\section{Optics and Beam Parameters}

In the following simulation we adopt the Blue ring lattice for $250 \mathrm{GeV}$ RHIC polarized proton run. Table 1 gives the optics and beam parameters for the proton beam for this study. The proton beams collide at IP6 and IP8 where $\beta^{*}$ s are about $0.5 \mathrm{~m}$. $\beta^{*} \mathrm{~s}$ at all other non-colliding IPs are about $10 \mathrm{~m}$. The normalized rms transverse emittance $\epsilon_{n}$ is $2.5 \mathrm{~mm} . \mathrm{mrad}$. The longitudinal beam area is $0.17 \mathrm{eV} . \mathrm{s}$, which gives rms beam momentum spread $0.14 \times 10^{-3}$ and the $\mathrm{rms}$ bunch length $0.44 \mathrm{~m}$.

So far we haven't demonstrated $250 \mathrm{GeV}$ polarized proton run with $\beta^{*}=0.5 \mathrm{~m}$ in the RHIC. In the $2009250 \mathrm{GeV}$ RHIC polarized proton run, the $\beta^{*} \mathrm{~s}$ at IP6 and IP8 were about $0.7 \mathrm{~m}$. Figure 2 shows the $\beta$ function and horizontal dispersion along the ring with the $\beta^{*}=0.5 \mathrm{~m}$ lattice. The $\beta^{*}$ at IP6 and IP8 from the lattice model are actually about $0.53 \mathrm{~m}$ for this lattice. From Figure 2, there are about $\pm 1.0 \mathrm{~m}$ horizontal dispersion in the IR6 and IR8 which is different from the larger $\beta^{*}$ lattices we have used in the previous proton run. Therefore the lattice with $\beta^{*}=0.5 \mathrm{~m}$ in this study may need further optimization.

As we know, low $\beta^{*}$ lattice will increase the strengths of chromatic sextupoles to correct the increased natural linear chromaticity. The second order chromaticities will increase too. The second order chromaticity for the lattice are about $(2400,2700)$. For off-momentum particles with relative momentum deviation, the chromatic tune shift from the linear and the second order chromaticity are comparable. In this article we will investigate the effect of second order chromaticity correction with head-on beam-beam compensation.

From Table 1, with any beam-beam interaction, the horizontal and vertical betatron phase advances between IP6 and IP8 are $(10.6 \pi, 9.7 \pi)$. The phase advances between IP8 and the center of e-lens are $(8.5 \pi$, $11.1 \pi)$. The phase advances between IP6 and the center of e-lens are $(19.1 \pi, 19.6 \pi)$. To better compensate the nonlinearity from proton-proton collision at IP8 with the e-lens, we will adjust the betatron phase advances between IP8 and the center of e-lens to multipoles of $\pi$ in both the horizontal and vertical planes. After phase adjustment, the phase advances between IP8 and the center of e-lens will be $(9.0 \pi, 11.0 \pi)$.

\section{Beam-beam and compensation parameters}

The total linear beam-beam tune shift, or the total beam-beam parameter from proton-proton collisions at IP6 and IP8 is

$$
\xi_{p p}=-\frac{N_{p} r_{p}}{4 \pi \epsilon_{n}} \times N_{I P} .
$$

Here $r_{p}$ is the classic radius of proton. The number of proton-proton colliding points $N_{I P}=2$. In the fallowing dynamic aperture calculation we will focus on three bunch intensities $N_{p}=2.0 \times 10^{11}, 2.5 \times 10^{11}$ and $3.0 \times 10^{11}$. From Eq. (1), the total proton-proton beam-beam parameters with 2 colliding points are 
Table 1: Parameters for the proton beams

\begin{tabular}{|c|c|c|}
\hline quantity & unit & value \\
\hline \multicolumn{3}{|l|}{ lattice } \\
\hline ring circumference & $\mathrm{m}$ & 3833.8451 \\
\hline energy & $\mathrm{GeV}$ & 250 \\
\hline relativistic $\gamma$ & - & 266 \\
\hline proton-proton colliding points & - & IP6, IP8 \\
\hline location of e-lens & - & around IP10 \\
\hline$\beta_{x, y}^{*}$ at IP6 and IP8 & $\mathrm{m}$ & 0.53 \\
\hline$\beta_{x, y}^{e}$ at e-lens & $\mathrm{m}$ & 10.0 \\
\hline$\beta_{x, y}^{*}$ at all other IPs & $\mathrm{m}$ & 10.0 \\
\hline betatron phases between IP 6 and IP 8 & $(10.6 \pi, 9.7 \pi)$ & \\
\hline betatron phases between IP 6 and e-lens center & $(8.5 \pi, 11.1 \pi)$ & \\
\hline betatron phases between IP6 and e-lens center & $(19.1 \pi, 19.6 \pi)$ & \\
\hline \multicolumn{3}{|l|}{ transverse parameters } \\
\hline normalized transverse rms emittance $\epsilon_{x, y}$ & $\mathrm{~mm} \cdot \mathrm{mrad}$ & 2.5 \\
\hline transverse rms beam size at IP6 and IP $8 \sigma_{x, y}^{*}$ & $\mathrm{~mm}$ & 0.068 \\
\hline transverse rms beam size at e-lens $\sigma_{x, y}^{e}$ & $\mathrm{~mm}$ & 0.31 \\
\hline transverse tunes & $(28.67,29.68)$ & \\
\hline linear chromaticities & $(1,1)$ & \\
\hline second order chromaticities without correction & $(2400,2700)$ & \\
\hline proton-proton beam-beam parameter per IP & $-0.01 *\left(N_{p} / 1.0 \times 10^{11}\right)$ & \\
\hline \multicolumn{3}{|l|}{ longitudinal parameters } \\
\hline harmonic number & - & 360 \\
\hline rf cavity voltage & $\mathrm{kV}$ & 300 \\
\hline rms longitudinal bunch area & $\mathrm{eV} \cdot \mathrm{s}$ & 0.17 \\
\hline rms momentum spread & - & $0.14 \times 10^{-3}$ \\
\hline rms bunch length & $\mathrm{m}$ & 0.44 \\
\hline
\end{tabular}

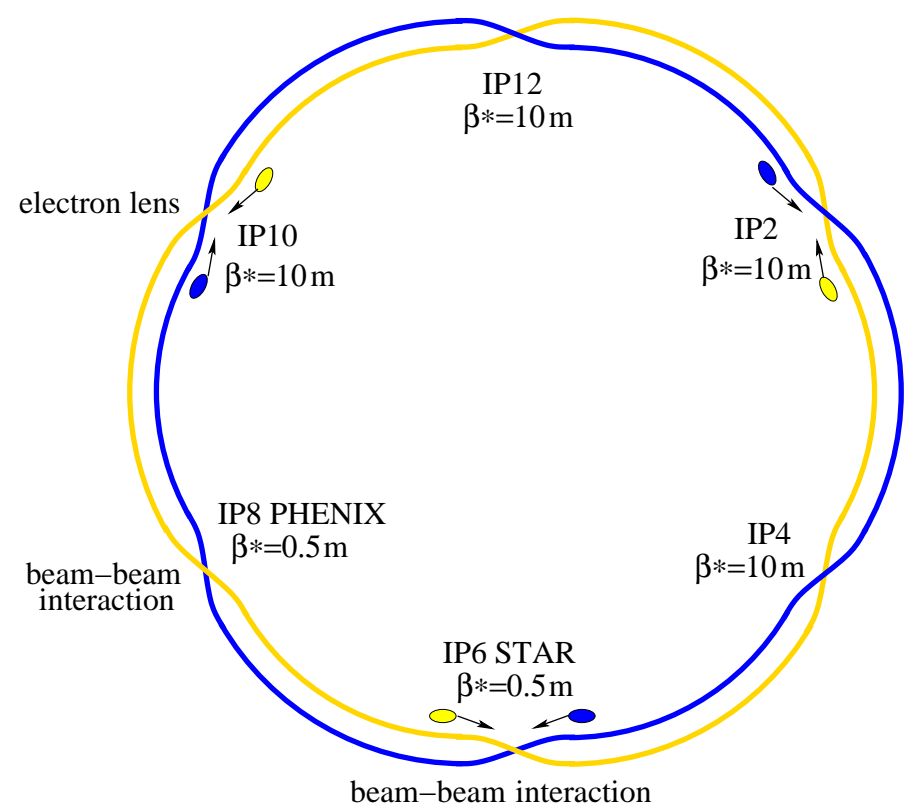

Figure 1: Layout of RHIC head-on beam-beam compensation. 


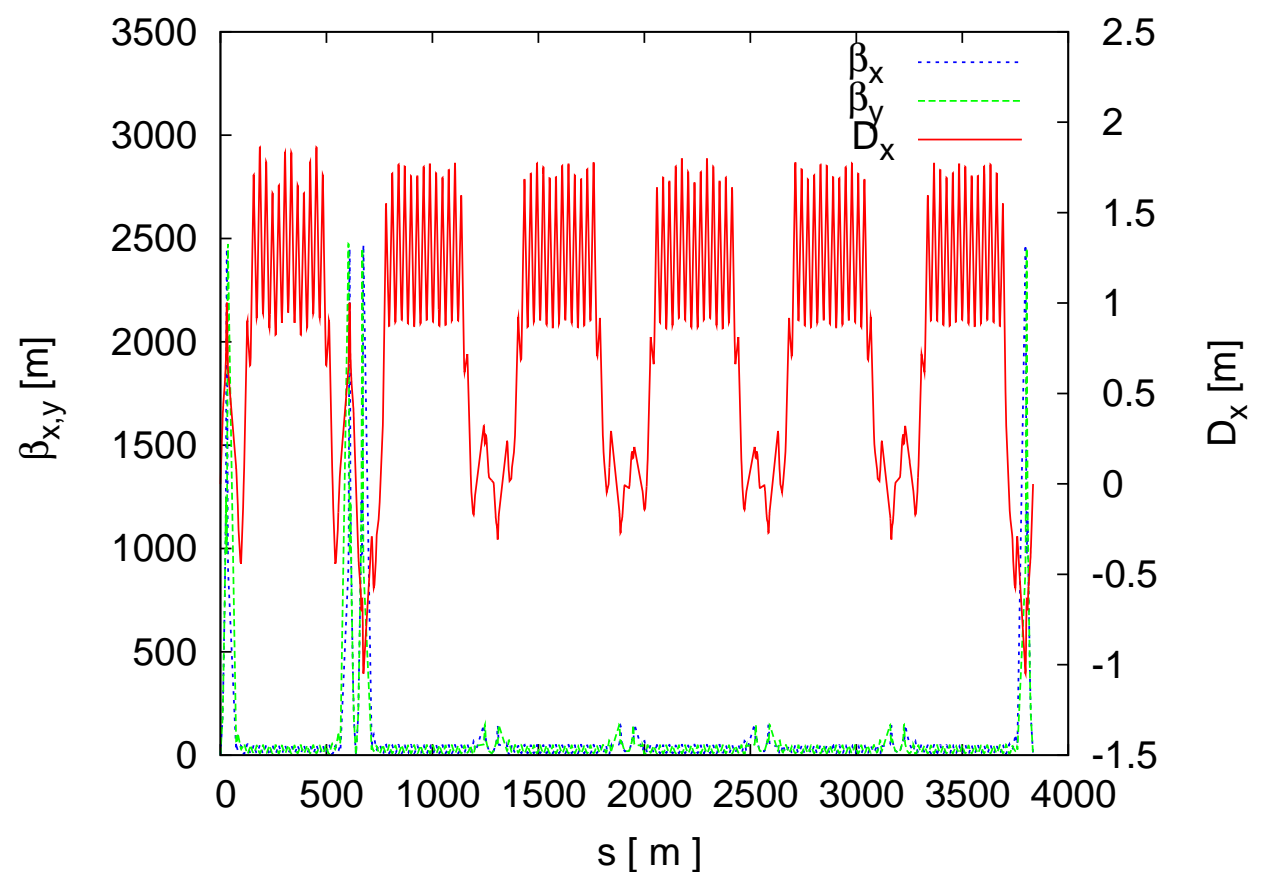

Figure 2: Layout of RHIC head-on beam-beam compensation.

about $-0.020,-0.024$, and -0.030 for bunch intensities $2.0 \times 10^{11}, 2.5 \times 10^{11}$ and $3.0 \times 10^{11}$ respectively. Clearly there is not enough room in the current RHIC polarized proton tune space $(2 / 3,7 / 10)$ to hold all the beam-beam tune shift and tune spread generated by the proton-proton collisions with bunch intensity above $2.0 \times 10^{11}$.

In the current design, the e-lenses are to be placed $1 \mathrm{~m}$ north in the Blue ring and $1 \mathrm{~m}$ south in the Yellow ring around IP10. The effective electron-proton interaction length is $2 \mathrm{~m}$ long. We define full and half head-on beam-beam compensations to compensate full or half total proton-proton beam-beam parameter. In the following study, we will mainly focus on the half beam-beam compensation. The full head-on beam-beam compensation introduces too much nonlinearities into the proton beam dynamic and therefore deteriorates the proton particle's dynamic aperture. Figure 1 is the schematic plot of the head-on beam-beam compensation in the RHIC.

\section{Tracking Setup}

We will numerically calculate the dynamic apertures and compare them under different beam-beam conditions. Dynamic aperture is defined as the maximum transverse amplitude below which the particles will survive in a long-term tracking. It is oan important indicator to predict the beam lifetime imposed by the nonlinear beam dynamics. Of course, due to the fact that dynamic aperture is calculated for certain particles and a limited tracking turns, it doesn't reflect the survival map of all particles in the bunch. And the dynamic aperture doesn't hint emittance growth.

In this note we will track particles in 5 phase angles in the first quadrant in the $\mathrm{x}$-y plane. The initial transverse momenta and the initial time delay of test particles are set to zero. The initial relative momentum deviation will be $d p / p=0$ ( on-momentum) or 0.0005 . The starting point of tracking is IP6. The particles are to be tracked up to $10^{6}$ turns. The dynamic apertures are measured in units of rms transverse beam size $\sigma=\sqrt{\epsilon_{n} \beta^{*} / \gamma}$. Since there are some differences in the dynamic apertures searched in different phase angles, we will focus on comparison of the minimum dynamic aperture among these 5 phase angles.

Considering $\beta^{*}$ is comparable to the bunch length at IP6 and IP8, the 6-D weak-strong synchro-beam map a la Hirata [3] is used to calculate the proton-proton beam-beam interactions. The e-lens will be split into 8 slices and for each slice, considering the electron beam is a DC beam, a drift- $4 \mathrm{D}$ weak-strong beambeam kick)-drift model is used to calculate the forces the proton test particles get from the electron beam. The 4D weak-strong beam-beam kick is based on the equation by Bassetti-Erskine [4]. The strong proton beam in another ring and the electron beam are considered rigid and will not be affected by the test particles 
Table 2: Calculated dynamic aperture with one and two proton-proton collisions.

\begin{tabular}{lcccccccc}
\hline \hline Bunch intensity & p-p & $d p / p_{0}$ & \multicolumn{5}{c}{ Dynamic aperture } \\
& interaction points & & $15^{\circ}$ & $30^{\circ}$ & $45^{\circ}$ & $60^{\circ}$ & $75^{\circ}$ & Minimum \\
\hline $2.0 \mathrm{e} 11$ & IP6 & 0.0 & 9.4 & 7.7 & 7.1 & 6.1 & 8.3 & 6.1 \\
$2.5 \mathrm{e} 11$ & IP6 & 0.0 & 9.4 & 8.1 & 7.7 & 6.9 & 8.6 & 6.9 \\
$3.0 \mathrm{e} 11$ & IP6 & 0.0 & 9.4 & 8.3 & 7.9 & 7.5 & 9.4 & 7.5 \\
$2.0 \mathrm{e} 11$ & IP6, IP8 & 0.0 & 9.4 & 7.7 & 7.9 & 7.9 & 8.3 & 7.7 \\
$2.5 \mathrm{e} 11$ & IP6, IP8 & 0.0 & 9.6 & 8.3 & 7.7 & 7.7 & 9.0 & 7.7 \\
$3.0 \mathrm{e} 11$ & IP6, IP8 & 0.0 & 9.4 & 7.1 & 7.5 & 7.7 & 8.1 & 7.1 \\
\hline $2.0 \mathrm{e} 11$ & IP6 & 0.0005 & 7.5 & 7.1 & 6.7 & 5.9 & 5.3 & 5.3 \\
$2.5 \mathrm{e} 11$ & IP6 & 0.0005 & 7.5 & 7.3 & 6.9 & 5.9 & 5.1 & 5.1 \\
$3.0 \mathrm{e} 11$ & IP6 & 0.0005 & 6.9 & 7.1 & 6.5 & 6.3 & 5.7 & 5.7 \\
$2.0 \mathrm{e} 11$ & IP6, IP8 & 0.0005 & 6.7 & 7.1 & 5.9 & 5.1 & 5.1 & 5.1 \\
$2.5 \mathrm{e} 11$ & IP6, IP8 & 0.0005 & 5.3 & 5.5 & 4.7 & 3.6 & 4.5 & 3.6 \\
$3.0 \mathrm{e} 11$ & IP6, IP8 & 0.0005 & 4.3 & 4.0 & 3.2 & 3.4 & 3.4 & 3.2 \\
\hline \hline
\end{tabular}

Table 3: Calculated dynamic apertures with half head-on beam-beam compensation

\begin{tabular}{lccccccc}
\hline \hline Bunch intensity & $d p / p_{0}$ & \multicolumn{6}{c}{ Dynamic aperture } \\
& & $15^{\circ}$ & $30^{\circ}$ & $45^{\circ}$ & $60^{\circ}$ & $75^{\circ}$ & Minimum \\
\hline $2.0 \mathrm{e} 11$ & 0.0 & 7.3 & 7.3 & 6.9 & 6.1 & 6.1 & 6.1 \\
$2.5 \mathrm{e} 11$ & 0.0 & 7.1 & 6.5 & 6.3 & 5.7 & 7.1 & 5.7 \\
$3.0 \mathrm{e} 11$ & 0.0 & 6.7 & 6.5 & 5.9 & 6.1 & 7.1 & 5.9 \\
$2.0 \mathrm{e} 11$ & 0.0005 & 6.3 & 6.1 & 5.7 & 4.7 & 4.7 & 4.7 \\
$2.5 \mathrm{e} 11$ & 0.0005 & 7.1 & 5.7 & 4.5 & 4.7 & 4.1 & 4.1 \\
$3.0 \mathrm{e} 11$ & 0.0005 & 5.7 & 6.3 & 4.9 & 4.9 & 4.3 & 4.3 \\
\hline \hline
\end{tabular}

in the simulation.

The particle motion in the magnetic elements is tracked with the 4th order symplectic integration by R. Ruth [5]. To save the time involved in the numeric tracking, we treat the multipoles as thin lenses. That is, the non-zero length multipoles will be replaced by drift-(multipole kick)-drift. Of course, the tunes and chromaticities will be re-matched to original ones before the dynamic aperture tracking. In the study the tunes are always set to $(28.67,29.68)$ and the linear chromaticities are set to $(+1,+1)$ with beam-beam and/or beam-beam compensation before tracking.

\section{Tracking results}

\subsection{Without beam-beam compensation}

First we calculate the dynamic aperture without head-on beam-beam compensation. For comparison, we calculate the dynamic apertures with one collision at IP6 and with two collisions at IP6 and IP8. Table 2 and Figure 3 show the calculated dynamic apertures in the 5 phase angles.

From Figure 3, for all three bunch intensities $N p=2.0 \times 10^{11}, 2.5 \times 10^{11}$ and $3.0 \times 10^{11}$, for the offmomentum particles with $d p / p=0.0005$, the dynamic apertures with two collisions are smaller than that with one collision. From Table 2, from one to two collisions, the minimum dynamic apertures drop about $1.5 \sigma$ and $2.5 \sigma$ for bunch intensities $2.5 \times 10^{11}$ and $3.0 \times 10^{11}$ respectively. The minimum dynamic apertures with two collisions are below $4 \sigma$ for bunch intensities $2.5 \times 10^{11}$ and $3.0 \times 10^{11}$ respectively.

From Figure 2, the calculated dynamic apertures are very unbalanced in the 5 phase angles. The minimum dynamic aperture always happens in the phase angle of $75^{\circ}$. This may be due to the fact that the linear lattice is not optimized and the the magnetic resonance driving terms are not compensated.

\subsection{With half beam-beam compensation}

In the following study the proton beams always collide at IP6 and IP8. Here we investigate the effect of half head-on beam-beam compensation on the dynamic aperture. As mentioned above, half head-on beam-beam 


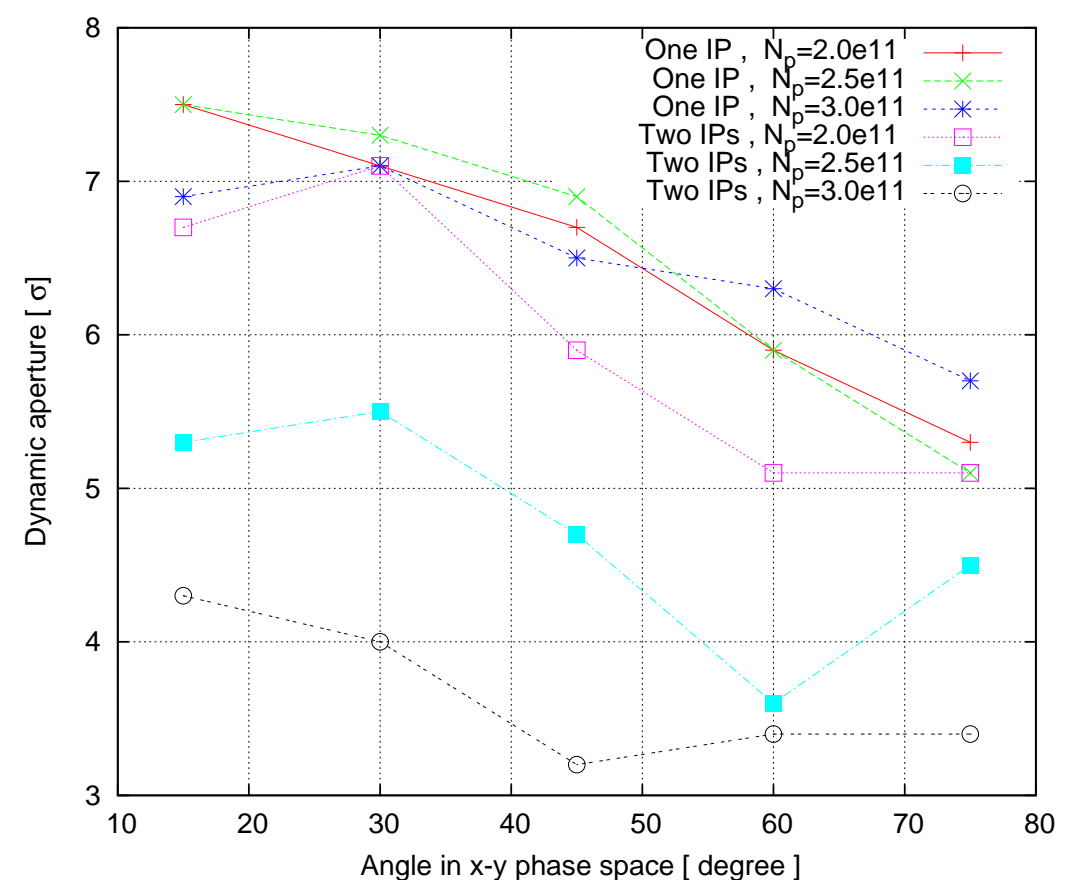

Figure 3: Calculated dynamic apertures with one or two proton-proton collisions.

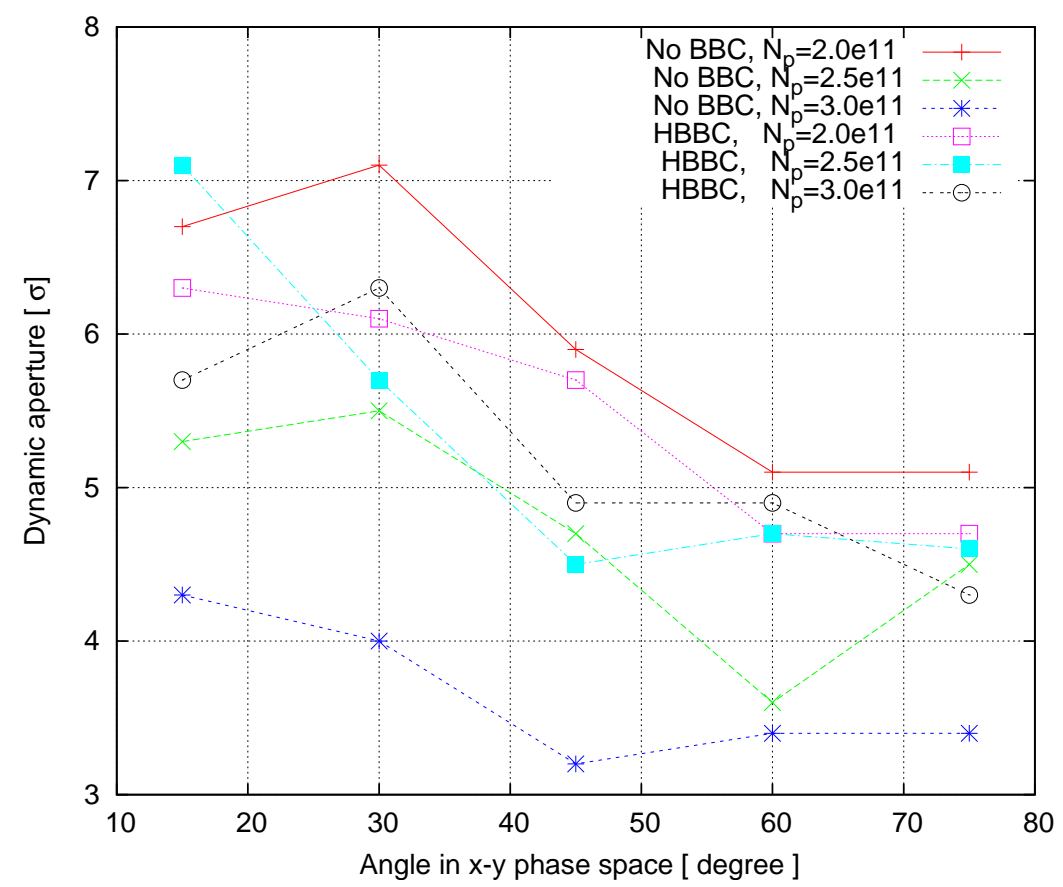

Figure 4: Calculated dynamic apertures with half head-on beam-beam compensation. 
Table 4: Calculated dynamic apertures with phase advances of $k \pi$ between IP8 and the center of the e-lens

\begin{tabular}{lccccccc}
\hline \hline Bunch intensity & $d p / p_{0}$ & \multicolumn{5}{c}{ Dynamic aperture } \\
& & $15^{\circ}$ & $30^{\circ}$ & $45^{\circ}$ & $60^{\circ}$ & $75^{\circ}$ & Minimum \\
\hline $2.0 \mathrm{e} 11$ & 0.0 & 6.7 & 6.9 & 6.5 & 6.9 & 6.1 & 6.1 \\
$2.5 \mathrm{e} 11$ & 0.0 & 6.5 & 6.9 & 6.5 & 6.7 & 6.5 & 6.5 \\
$3.0 \mathrm{e} 11$ & 0.0 & 6.1 & 5.9 & 6.1 & 5.9 & 6.7 & 5.9 \\
$2.0 \mathrm{e} 11$ & 0.0005 & 6.9 & 6.9 & 6.3 & 5.3 & 5.5 & 5.3 \\
$2.5 \mathrm{e} 11$ & 0.0005 & 6.7 & 6.5 & 6.1 & 5.3 & 4.9 & 4.9 \\
$3.0 \mathrm{e} 11$ & 0.0005 & 6.1 & 6.1 & 4.7 & 5.1 & 3.8 & 3.8 \\
\hline \hline
\end{tabular}

compensation compensates half linear proton-proton beam-beam tune shift. Table 3 and Figure 4 show the calculated dynamic apertures for the three bunch intensities.

Comparing Table 3 to Table 2 , for the off-momentum particles with $d p / p_{0}=0.0005$, half head-on beambeam compensation increases the minimum dynamic apertures by $0.5 \sigma$ and $1.1 \sigma$ for proton bunch intensities $2.5 \times 10^{11}$ and $3.0 \times 10^{11}$. However, for bunch intensities $2.0 \times 10^{11}$, the minimum dynamic aperture drops by $0.4 \sigma$ with half head-on beam-beam compensation.

\subsection{With adjusted phase advances}

For half head-on beam-beam compensation, to better compensate the nonlinearities from the proton-proton beam-beam interaction at IP8 with the e-lens around IP10, we will adjust the betatron phase advances between IP8 and the center of e-lens to be multiples of $\pi$. Without any beam-beam interaction and phase adjustment, the betatron phase advances between IP8 and the center of the e-lens are $(8.5 \pi, 11.1 \pi)$. In this study, we will adjust the betatron phase advances between IP 8 and the center of the e-lens to be $(7 \pi, 9 \pi)$.

To adjust the phase advances between IP8 and the e-lens, we insert two artificial betatron phase shift matrices before and after the e-lens in the lattice model. The phase shift matrices don't change the overall ring tunes and Twiss parameters. However, the exact $(7 \pi, 9 \pi)$ betatron phase advances are only true for on-momentum particles because of chromatic tune shift.

Table 4 shows the calculated dynamic apertures with half head-on beam-beam compensation and with phase advances of $k \pi$ between IP8 and the center of the e-lens. Figure 5 shows these dynamic apertures for the particles with $d p / p_{0}=0.0005$. In Figure 5 , for comparison, the dynamic apertures without phase adjustment from Table 3 are also shown.

Comparing Table 4 to Table 3, the phase advances of $k \pi$ between IP 8 and the center of the e-lens improve the minimum dynamic apertures by $0.8 \sigma$ for the on-momentum particles with bunch intensity $2.5 \times 10^{11}$. For bunch intensities $2.0 \times 10^{11}$ and $3.0 \times 10^{11}$, there is no improvement in the dynamic apertures of on-momentum particles.

For the off-momentum particles with $d p / p_{0}=0.0005$, the phase advances of $k \pi$ increase the minimum dynamic apertures by $0.6 \sigma$ and $0.3 \sigma$ for proton bunch intensities $2.0 \times 10^{11}$ and $2.5 \times 10^{11}$ respectively, but decrease the minimum dynamic aperture by $0.5 \sigma$ for bunch intensity $3.0 \times 10^{11}$.

\subsection{Scan of relative momentum deviation}

Here we scan the relative momentum deviation $d p / p_{0}$ with half head-on beam-beam compensation and phase advances of $k \pi$ between IP8 and e-lens. As we mentioned, the phase advances of $(7 \pi, 9 \pi)$ are only true for the on-momentum particles.

Figure 6 shows the minimum dynamic apertures in the scan of relative momentum deviation $d p / p_{0}$. From Figure 6, the on-momentum particles do have larger minimum dynamic apertures than the off-momentum particles. For proton bunch intensities of $2.5 \times 10^{11}$ and $3.0 \times 10^{11}$, the minimum dynamic apertures drop 1.5 - $2 \sigma$ from on-momentum particles to off-momentum particles with $d p / p_{0}= \pm 0.0005$.

\subsection{Scan of first order chromaticity}

Here we continue to scan the first order chromaticity Q' with half head-on beam-beam compensation and phase advances of $k \pi$ between IP8 and the e-lens. By adjusting first order chromaticities with chromatic sextupoles in the arcs, the off-momentum phase advances between IP8 and e-lens will be adjusted too. 


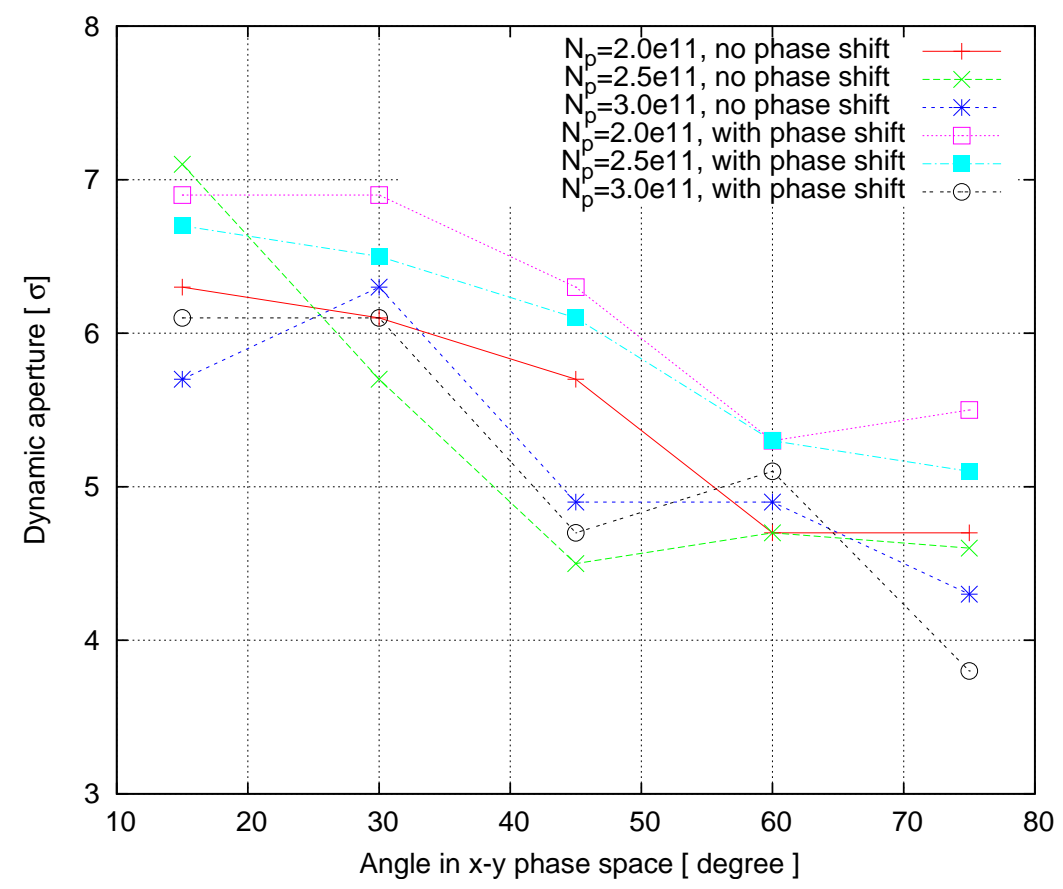

Figure 5: Calculated dynamic apertures withphase advances of $k \pi$ between IP8 and the center of the e-lens.

Table 5: Calculated dynamic apertures with second order chromaticity correction.

\begin{tabular}{lccccccc}
\hline \hline Bunch intensity & $d p / p_{0}$ & \multicolumn{5}{c}{ Dynamic aperture } \\
& & $15^{\circ}$ & $30^{\circ}$ & $45^{\circ}$ & $60^{\circ}$ & $75^{\circ}$ & Minimum \\
\hline $2.0 \mathrm{e} 11$ & 0.0 & 8.3 & 6.9 & 6.7 & 6.9 & 6.1 & 6.1 \\
$2.5 \mathrm{e} 11$ & 0.0 & 6.9 & 6.7 & 6.3 & 7.1 & 7.5 & 6.3 \\
$3.0 \mathrm{e} 11$ & 0.0 & 6.1 & 5.9 & 5.9 & 6.1 & 6.9 & 5.9 \\
$2.0 \mathrm{e} 11$ & 0.0005 & 6.7 & 6.7 & 6.1 & 5.7 & 5.5 & 5.5 \\
$2.5 \mathrm{e} 11$ & 0.0005 & 6.5 & 6.5 & 6.3 & 5.3 & 4.5 & 4.5 \\
$3.0 \mathrm{e} 11$ & 0.0005 & 6.5 & 6.3 & 6.1 & 4.5 & 3.8 & 3.8 \\
\hline \hline
\end{tabular}

Figure 7 shows the minimum dynamic apertures of off-momentum particles with $d p / p_{0}=0.0005$ in the scan of linear chromaticities from -2 to +4 . From Figure 7 , for the bunch intensity $2.0 \times 10^{11}$ and $2.5 \times 10^{11}$, the peak minimum dynamic apertures happen at zero linear chromaticity. For bunch intensities $3.0 \times 10^{11}$, it is hard to conclude where the peak minimum dynamic aperture is.

\subsection{With second order chromaticity correction}

Here we investigate the effect of the second order chromaticity $Q^{\prime \prime}$ on the dynamic aperture with half head-on beam-beam compensation and multipole phase advances of $k \pi$ between IP8 and e-lens. In the simulation, we used the convenient 4 knobs suggested in Ref. [6] to minimize the second order chromaticities. After correction, the second order chromaticities in both the horizontal and vertical planes are below 500. In this study, the sextupole resonance driving terms are not minimized.

Table 5 shows the calculated dynamic apertures with $Q^{\prime \prime}$ corrections for particles. Figure 8 shows the calculated dynamic aperture with $Q^{\prime \prime}$ corrections for particles with $d p / p_{0}=0.0005$. Comparing Table 5 to Table 4 , for the off-momentum particles with $d p / p_{0}=0.0005$, there are clear dynamic aperture increase for the proton bunch intensity $3.0 \times 10^{11}$ in three angles of $15^{\circ}, 30^{\circ}$ and $45^{\circ}$. For proton bunch intensities $2.0 \times 10^{11}$, second order chromaticity correction improves the minimum dynamic aperture by $0.2 \sigma$. For proton bunch intensities $2.5 \times 10^{11}$, second order chromaticity correction decreases the minimum dynamic aperture by $0.4 \sigma$. 


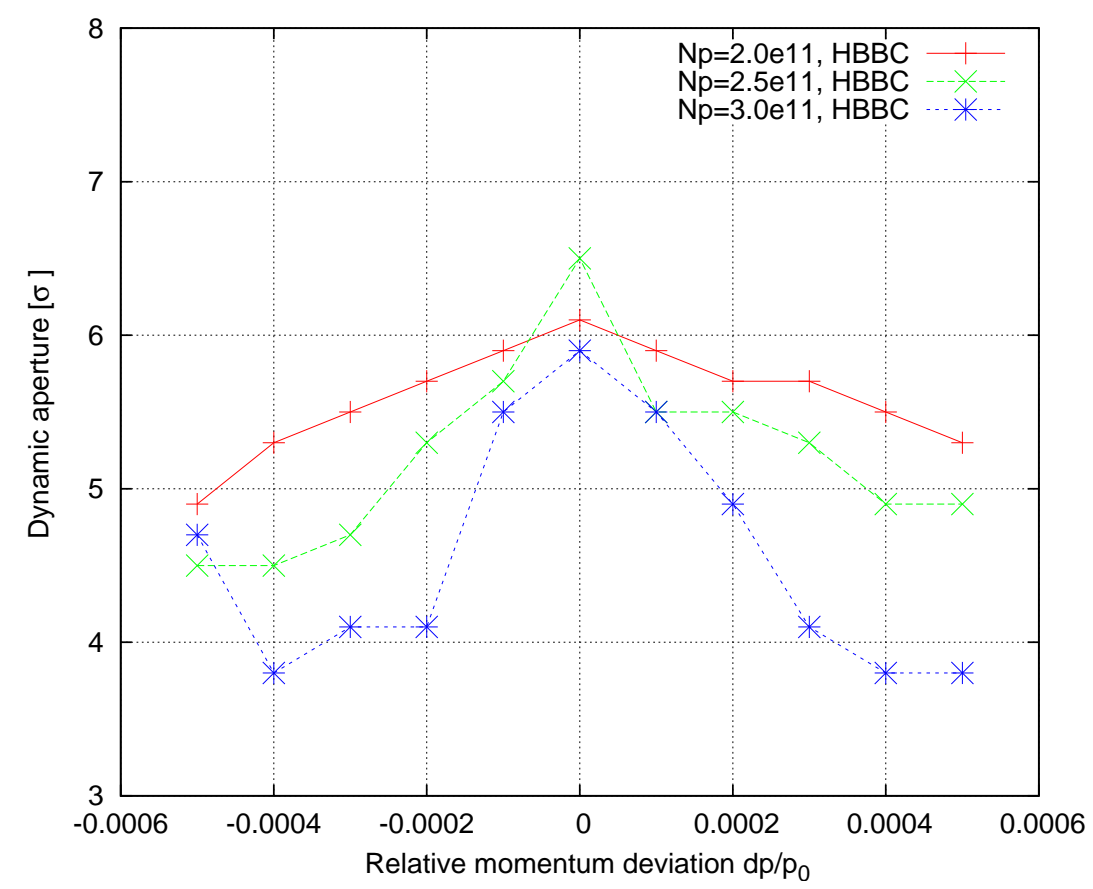

Figure 6: Calculated minimum dynamic apertures in the scan of relative momentum deviation $d p / p_{0}$.

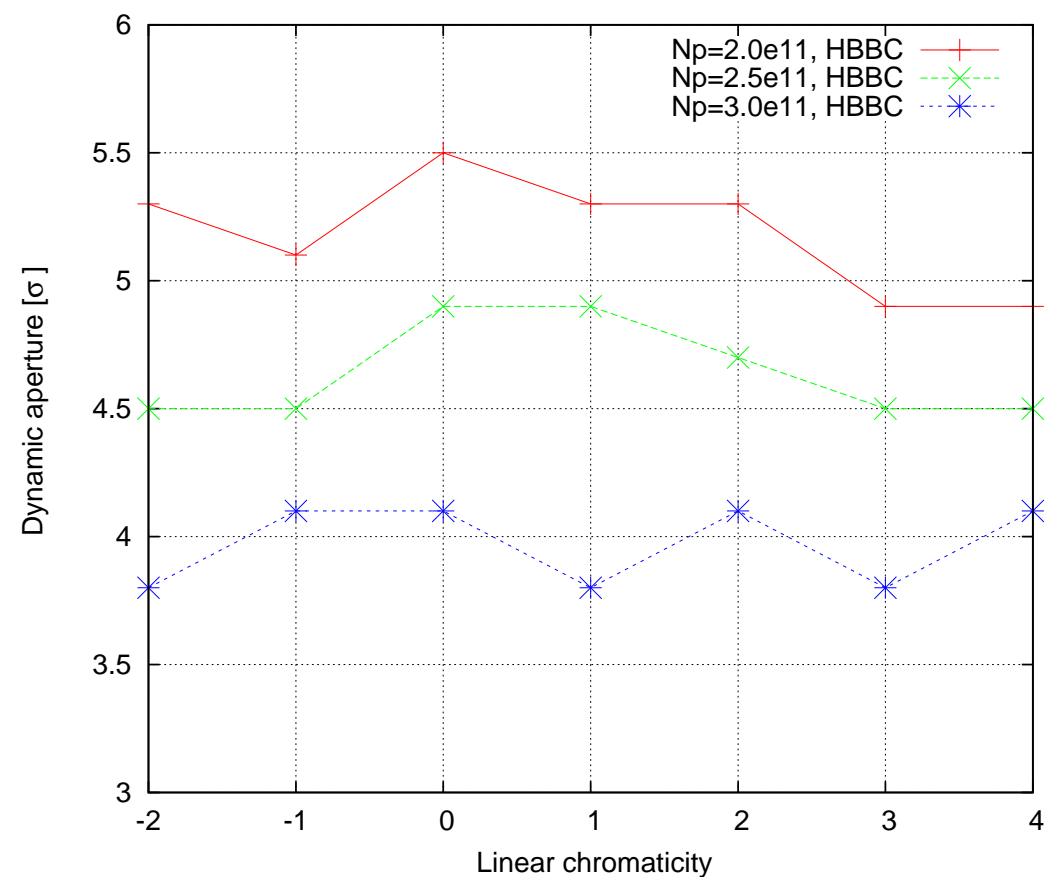

Figure 7: Calculated minimum dynamic aperture in the scan of linear chromaticity.

Table 6: Calculated minimum dynamic apertures in the proton tune scan

\begin{tabular}{lccc}
\hline \hline proton tunes & $N_{p}=2.0 \times 10^{11}$ & $N_{p}=2.5 \times 10^{11}$ & $N_{p}=3.0 \times 10^{11}$ \\
$(28.670,29.675)$ & 5.3 & 4.9 & 5.5 \\
$(28.675,29.680)$ & 5.7 & 4.7 & 3.8 \\
$(28.680,29.685)$ & 4.3 & 4.7 & 3.8 \\
$(28.675,29.670)$ & 5.3 & 5.7 & 5.5 \\
$(28.680,29.675)$ & 5.9 & 5.5 & 5.1 \\
$(28.685,29.680)$ & 4.3 & 4.3 & 3.8 \\
\hline \hline
\end{tabular}




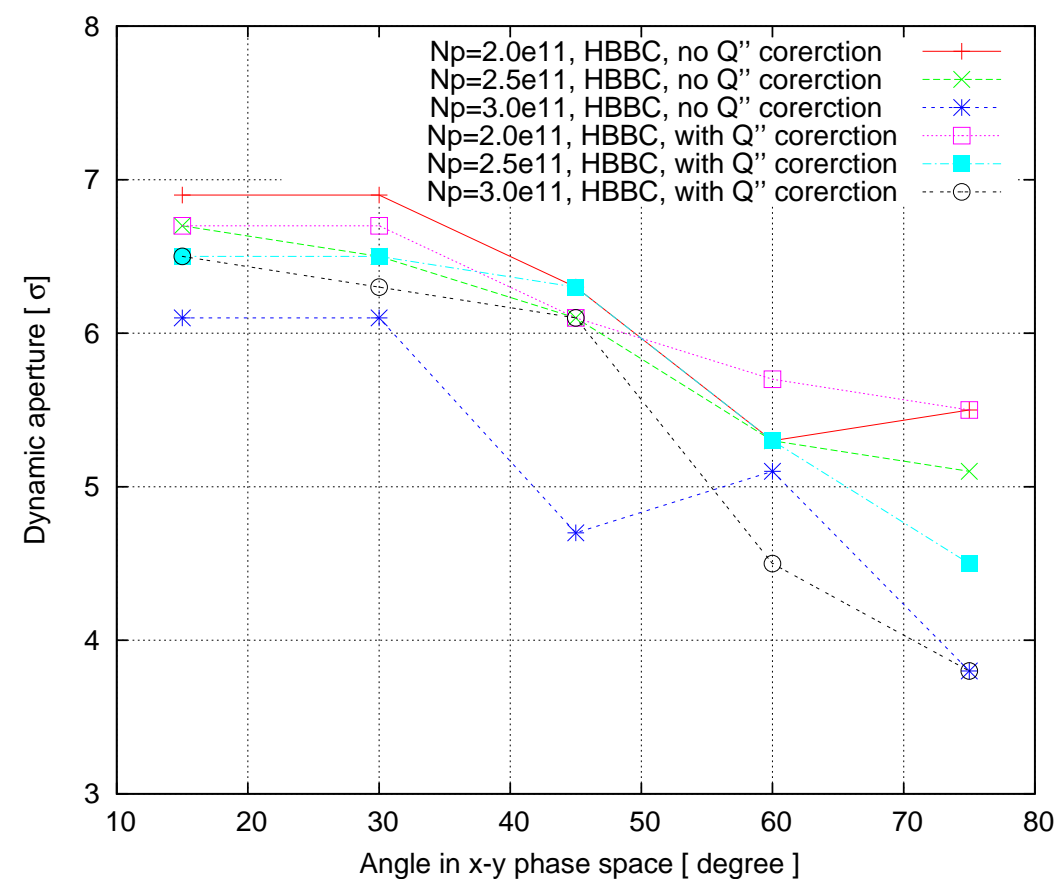

Figure 8: Calculated dynamic aperture with second order chromaticity correction.

\subsection{Scan of the proton beam working point}

In the above simulation we calculate the dynamic aperture with fixed collisional tunes $(28.67,29.68)$. Here we scan the proton tunes along the diagonal in the tune space. Due to the limited tune space between $2 / 3$ and $7 / 10$, actually we only can scan several working points along the diagonal. In this study the difference of the transverse tunes is 0.005 .

Table 6 shows the calculated dynamic aperture in the proton tune scan for the three proton bunch intensities. The shown tunes in Table 6 are the tunes including beam-beam and half beam-beam compensation. Phase advances of $k \pi$ between IP8 and the center of the e-lens and the second order chromaticity correction are included. From Table 6, in most cases the minimum dynamic apertures of tunes below diagonal are larger than those with swapped above diagonal tunes. And lower working points give larger minimum dynamic apertures.

\subsection{Scan of the proton bunch intensity}

Here we scan of the proton bunch intensity with different bam-beam compensation conditions: without beam-beam compensation, with half beam-beam compensation, with phase advances of $k \pi$ between IP 8 and the center of the e-lens, and with the second order chromaticity correction.

Figure 9 shows the minimum dynamic apertures in the scan of proton bunch intensities from $1.2 \times 10^{11}$ to $3.0 \times 10^{11}$. From Figure 9, below a proton bunch intensity of $2.0 \times 10^{11}$, half beam-beam compensation doesn't help improve the dynamic aperture. Also from Figure 9, for proton bunch intensity from $2.0 \times 10^{11}$ to $2.5 \times 10^{11}$, phase advances of $k \pi$ between IP 8 and the center of the e-lens increase the minimum dynamic apertures. And the second order chromaticity correction increases the minimum dynamic apertures with bunch intensity from $2.0 \times 10^{11}$ up to $2.8 \times 10^{11}$.

\subsection{Scan of the head-on beam-beam compensation strength}

Here we scan the beam-beam compensation strength, that is, the electron beam intensity in the e-lens. We define the compensation strength as the electron beam intensity divided by twice the proton bunch intensity. For half and full head-on beam-beam compensations, the compensation strength are 0.5 and 1.0 respectively.

Figure 10 shows the minimum dynamic aperture in the scan of the compensation strength. In this study, phase advances of $k \pi$ between IP8 and the center of the e-lens and the second order chromaticity correction are included. From Figure 10, compensation with compensation strength above 0.7 reduces the dynamic 


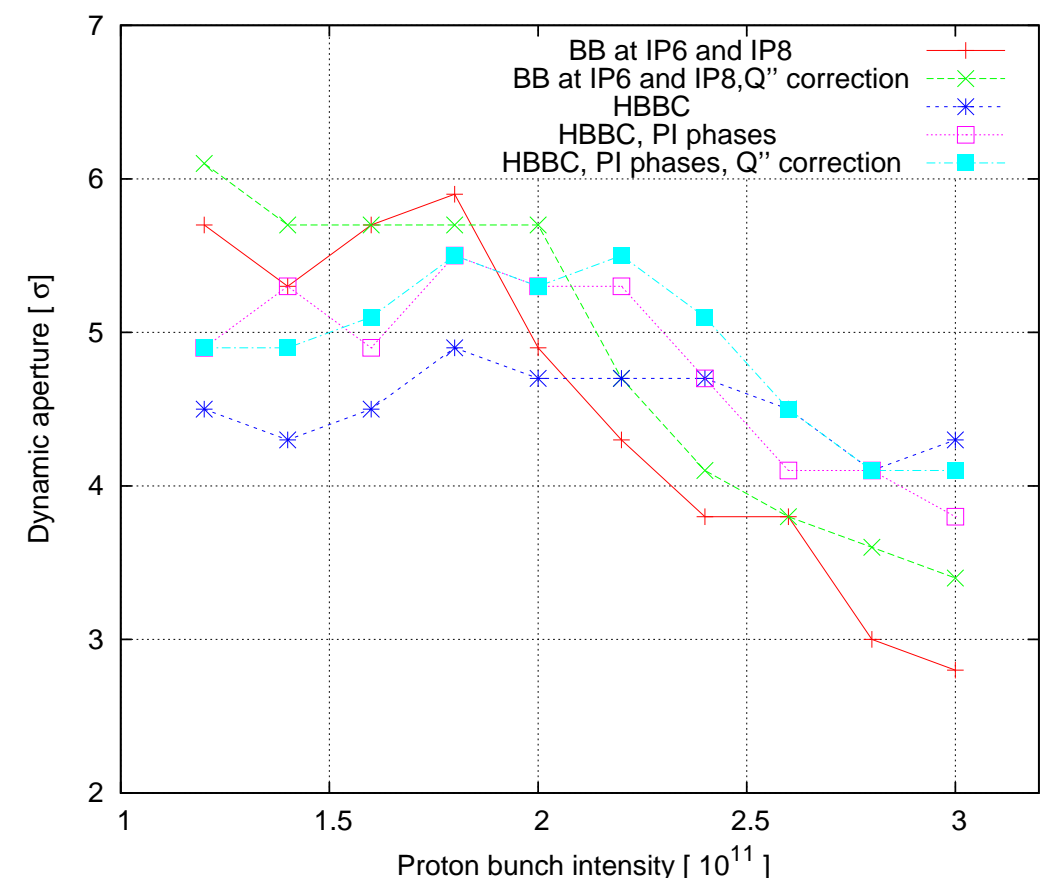

Figure 9: Calculated minimum dynamic aperture with half head-on beam-beam compensation in the scan of proton bunch intensity

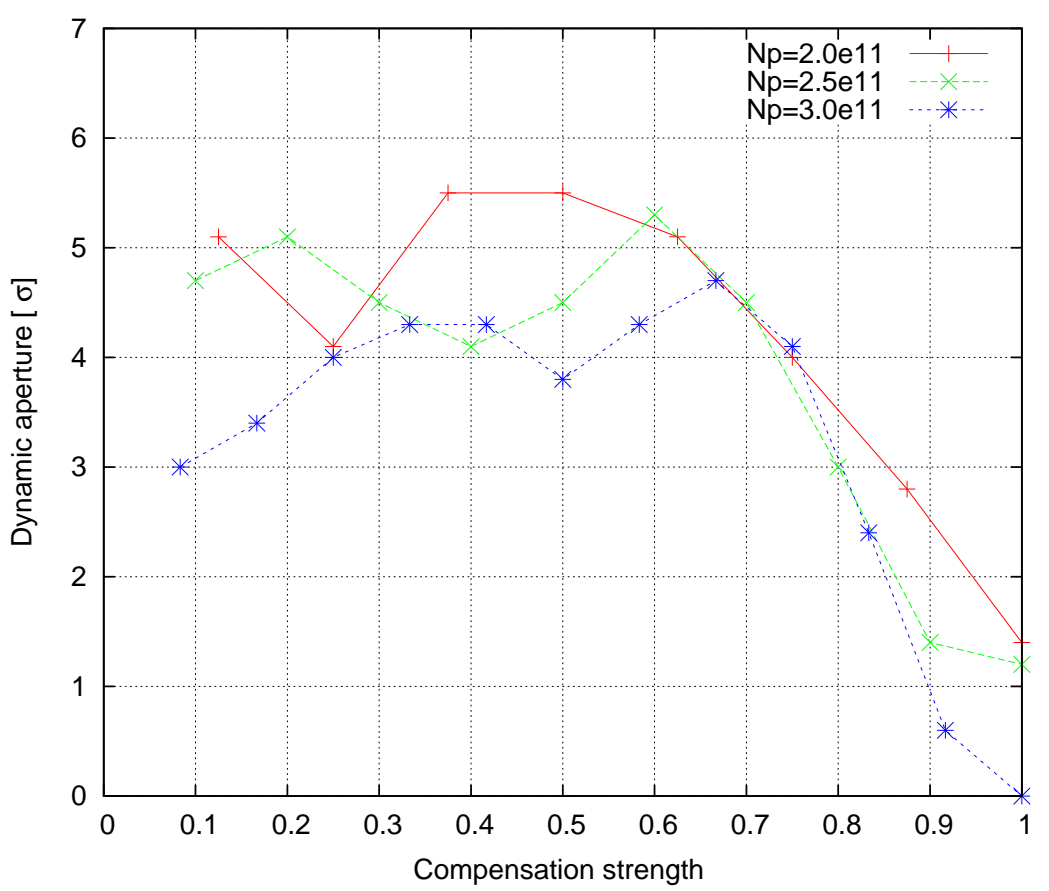

Figure 10: Calculated minimum dynamic aperture versus the compensation strength. 


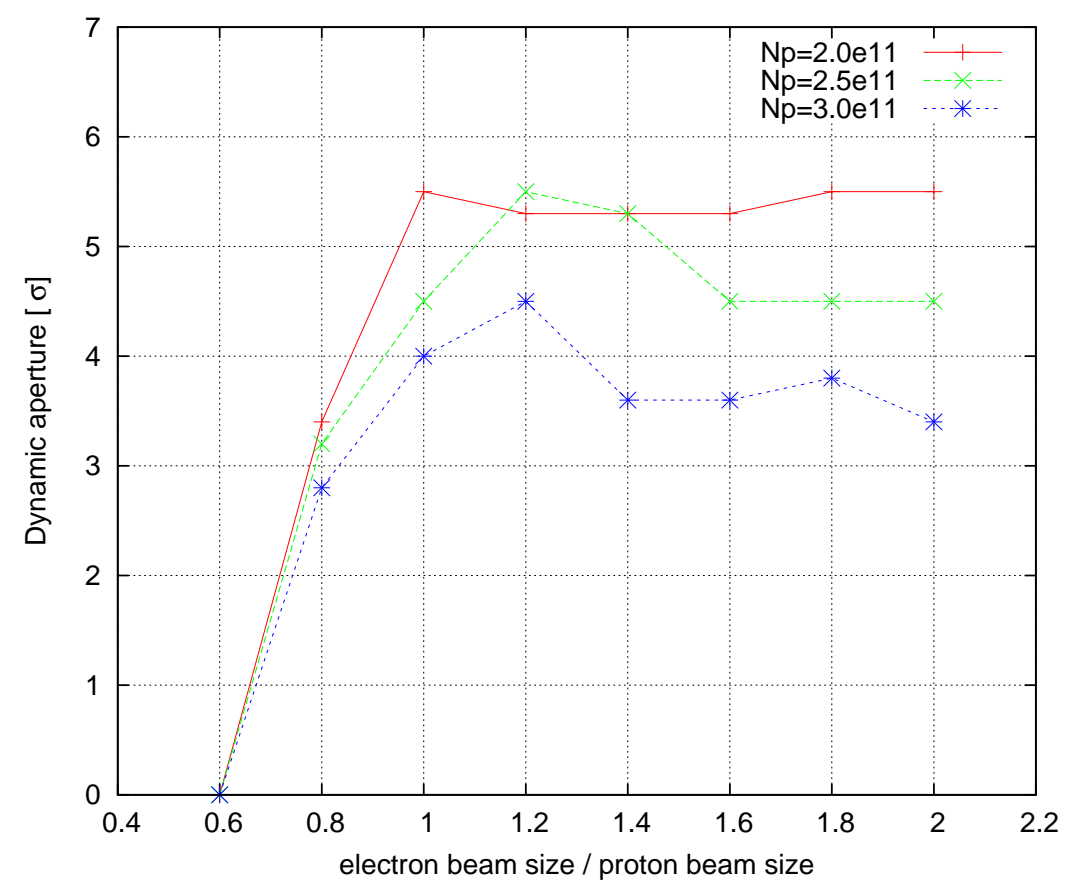

Figure 11: Calculated minimum dynamic aperture versus electron beam size.

aperture for all the three bunch intensities. For bunch intensity $2.0 \times 10^{11}$, the peak minimum dynamic aperture occurs at compensation strength 0.4 0.5, while for bunch intensities $2.5 \times 10^{11}$ and $3.0 \times 10^{11}$, the peak minimum dynamic aperture occur at compensation strength 0.60 .65 .

\subsection{Scan of the electron beam size}

Here we scan the electron beam size with half head-on beam-beam compensation. Figure 11 shows the calculated minimum dynamic aperture versus the electron beam size divided by the proton beam size. Phase advances of $k \pi$ between IP 8 and the center of the e-lens and the second order chromaticity correction are included.

From Figure 11, the dynamic aperture quickly drops when the electron beam size is smaller than that of proton bunch. The peak minimum dynamic aperture happen when the electron beam size is $20 \tilde{4} 0 \%$ bigger than the proton bunch's.

\section{Summary}

In this note we calculated and compared the dynamic apertures with head-on beam-beam compensation with the Blue ring $250 \mathrm{GeV}$ proton run lattice. The $\beta^{*} \mathrm{~s}$ are IP6 and IP8 are nominally $0.5 \mathrm{~m}$. For off-momentum particles with relative momentum deviation $d p / p_{0}=0.0005$, the half head-on beam-beam compensation improves the minimum dynamic aperture with proton bunch intensities above $2.0 \times 10^{11}$. Phase advances of multiples of $\pi$ between IP8 and the e-lens and the second order chromaticity correction also increase the minimum dynamic apertures with bunch intensity from $2.0 \times 10^{11}$ up to $2.8 \times 10^{11}$. The proton tune scan shows that working points below the diagonal give higher dynamic apertures than the working points above the diagonal. A slightly larger electron beam size than the proton's yields larger proton dynamic aperture. The scan of the compensation strength hints that around half beam-beam compensation is the optimum to apply the head-on beam-beam compensation.

In this note we used the dynamic aperture as the observable to judge the effect of head-on beam-beam compensation. And most of the time we were only using the dynamic apertures of the off-momentum particles with relative momentum deviation $d p / p_{0}=0.0005$. Therefore, the conclusion based these particles may not reflect to the behaviors of the whole proton beam. Also, the dynamic aperture doesn't provide any information about the action dilution of particles and emittance growth of the bunch. To confirm the observations from dynamic aperture calculation, multi-particle tracking is necessary. 
All the simulations in the note were done with SimTrack [7]. SimTrack is a c++ library for optical calculation and particle tracking in high energy circular accelerators.

\section{References}

[1] V. Shiltsev, Electron lenses in Tevatron, RHIC and LHC, in the 2005 RHIC APEX workshop, BNL, November 2005.

[2] Y. Luo, W. Fischer, Outline of using an electron lens for the RHIC head-on beam-beam compensation, BNL C-AD AP Note 286, July 2007.

[3] K. Hirata, H. Moshammer, F. Ruggiero, A symplectic beam-beam interaction with energy change, Particle Accel. 40 (1993) 205-228.

[4] M. Bassetti and G.A. Erskine, Closed expression for the electricalfield of a two-dimensional Gaussian charge, CERN-ISR-TH/80-06.

[5] R.D. Ruth, "A canonical Integration Technique", IEEE Trans. Nucl. Sci., vol. NS-30, PP.2669-2671 (1983).

[6] Y. Luo, et al., Sorting chromatic sextupoles for easily and effectively correcting second order chromaticity in the Relativistic Heavy Ion Collider, BNL C-A/AP/348, January, 2009.

[7] Y. Luo, SimTrack User's Mannual ( v1.0 ), BNL C-AD AP Note 388, January, 2010. 


\section{Appendix I: DAs with 6-D beam-beam treatment}

Subject: Evaluation of dynamic aperture in presence of head-on beam-beam compensation in RHIC $\mathrm{BB}$ at IP6 and IP8: 6-D weak-strong

E-lens : 4-D weak-strong with 6-8 integrations

\begin{tabular}{|c|c|c|c|c|c|}
\hline JobID & NP & $\mathrm{BB}$ & DELTA & $Q^{\prime}$ & $\mathrm{DA}(15 / 30 / 45 / 60 / 75 /$ minimum $)$ \\
\hline
\end{tabular}

Only BB at IP6:

$\begin{array}{llllllllllll}39 & 2.0 \mathrm{e} 11 & 6 \mathrm{D} & 0.0 & .67 / .68 & 1 / 1 & 9.4 & 7.7 & 7.1 & 6.1 & 8.3 & 6.1 \\ 40 & 2.5 \mathrm{e} 11 & \text { 6D } & 0.0 & .67 / .68 & 1 / 1 & 9.4 & 8.1 & 7.7 & 6.9 & 8.6 & 6.9 \\ 41 & 3.0 \mathrm{e} 11 & 6 \mathrm{D} & 0.0 & .67 / .68 & 1 / 1 & 9.4 & 8.3 & 7.9 & 7.5 & 9.4 & 7.5 \\ & & & & & & & & & & & \\ 42 & 2.0 \mathrm{e} 11 & 6 \mathrm{D} & 0.0005 & .67 / .68 & 1 / 1 & 7.5 & 7.1 & 6.7 & 5.9 & 5.3 & 5.3 \\ 43 & 2.5 \mathrm{e} 11 & 6 \mathrm{D} & 0.0005 & .67 / .68 & 1 / 1 & 7.5 & 7.3 & 6.9 & 5.9 & 5.1 & 5.1 \\ 44 & 3.0 \mathrm{e} 11 & \text { 6D } & 0.0005 & .67 / .68 & 1 / 1 & 6.9 & 7.1 & 6.5 & 6.3 & 5.7 & 5.7\end{array}$

Only BB at IP6 and IP8:

$\begin{array}{llllllllllll}45 & 2.0 \mathrm{e} 11 & 6 \mathrm{D} & 0.0 & .67 / .68 & 1 / 1 & 9.4 & 7.7 & 7.9 & 7.9 & 8.3 & 7.7 \\ 46 & 2.5 \mathrm{e} 11 & 6 \mathrm{D} & 0.0 & .67 / .68 & 1 / 1 & 9.6 & 8.3 & 7.7 & 7.7 & 9.0 & 7.7 \\ 47 & 3.0 \mathrm{e} 11 & 6 \mathrm{D} & 0.0 & .67 / .68 & 1 / 1 & 9.4 & 7.1 & 7.5 & 7.7 & 8.1 & 7.1 \\ & & & & & & & & & & & \\ 48 & 2.0 \mathrm{e} 11 & 6 \mathrm{D} & 0.0005 & .67 / .68 & 1 / 1 & 6.7 & 7.1 & 5.9 & 5.1 & 5.1 & 5.1 \\ 49 & 2.5 \mathrm{e} 11 & 6 \mathrm{D} & 0.0005 & .67 / .68 & 1 / 1 & 5.3 & 5.5 & 4.7 & 3.6 & <6.3> & 3.6 \\ 50 & 3.0 \mathrm{e} 11 & 6 \mathrm{D} & 0.0005 & .67 / .68 & 1 / 1 & 4.3 & 4.0 & 3.2 & 3.4 & 3.4 & 3.2\end{array}$

HBBC No phasers:

$\begin{array}{llllllllllll}1 & 2.0 \mathrm{e} 11 & 6 \mathrm{D} & 0.0 & .67 / .68 & 1 / 1 & 7.3 & 7.3 & 6.9 & 6.1 & 6.1 & 6.1 \\ 2 & 2.5 \mathrm{e} 11 & 6 \mathrm{D} & 0.0 & .67 / .68 & 1 / 1 & 7.1 & 6.5 & 6.3 & 5.7 & 7.1 & 5.7 \\ 3 & 3.0 \mathrm{e} 11 & 6 \mathrm{D} & 0.0 & .67 / .68 & 1 / 1 & 6.7 & 6.5 & 5.9 & 6.1 & 7.1 & 5.9 \\ & & & & & & & & & & & \\ 4 & 2.0 \mathrm{e} 11 & 6 \mathrm{D} & 0.0005 & .67 / .68 & 1 / 1 & 6.3 & 6.1 & 5.7 & 4.7 & 4.7 & 4.7 \\ 5 & 2.5 \mathrm{e} 11 & 6 \mathrm{D} & 0.0005 & .67 / .68 & 1 / 1 & 7.1 & 5.7 & 4.5 & 4.7 & 4.1 & 4.1 \\ 6 & 3.0 \mathrm{e} 11 & 6 \mathrm{D} & 0.0005 & .67 / .68 & 1 / 1 & 5.7 & 6.3 & 4.9 & 4.9 & 4.3 & 4.3\end{array}$

HBBC with PI phasers:

$\begin{array}{llllllllllll}7 & 2.0 \mathrm{e} 11 & 6 \mathrm{D} & 0.0 & .67 / .68 & 1 / 1 & 6.7 & 6.9 & 6.5 & 6.9 & 6.1 & 6.1 \\ 8 & 2.5 \mathrm{e} 11 & 6 \mathrm{D} & 0.0 & .67 / .68 & 1 / 1 & 6.5 & 6.9 & 6.5 & 6.7 & 6.5 & 6.5 \\ 9 & 3.0 \mathrm{e} 11 & 6 \mathrm{D} & 0.0 & .67 / .68 & 1 / 1 & 6.1 & 5.9 & 6.1 & 5.9 & 6.7 & 5.9 \\ & & & & & & & & & & & \\ 10 & 2.0 \mathrm{e} 11 & 6 \mathrm{D} & 0.0005 & .67 / .68 & 1 / 1 & 6.9 & 6.9 & 6.3 & 5.3 & 5.5 & 5.3 \\ 11 & 2.5 \mathrm{e} 11 & 6 \mathrm{D} & 0.0005 & .67 / .68 & 1 / 1 & 6.7 & 6.5 & 6.1 & 5.3 & 4.9 & 4.9 \\ 12 & 3.0 \mathrm{e} 11 & 6 \mathrm{D} & 0.0005 & .67 / .68 & 1 / 1 & 6.1 & 6.1 & 4.7 & 5.1 & 3.8 & 3.8\end{array}$




$\begin{array}{llllllllllll}400 & 2.0 \mathrm{e} 11 & 6 \mathrm{D} & -0.0005 & .67 / .68 & 1 / 1 & 6.1 & 6.1 & 6.3 & 5.5 & 4.9 & 4.9 \\ 401 & 2.0 \mathrm{e} 11 & 6 \mathrm{D} & -0.0004 & .67 / .68 & 1 / 1 & 6.5 & 6.5 & 6.1 & 5.3 & 5.5 & 5.3 \\ 402 & 2.0 \mathrm{e} 11 & 6 \mathrm{D} & -0.0003 & .67 / .68 & 1 / 1 & 6.5 & 6.3 & 6.3 & 5.5 & 5.7 & 5.5 \\ 403 & 2.0 \mathrm{e} 11 & 6 \mathrm{D} & -0.0002 & .67 / .68 & 1 / 1 & 6.5 & 6.7 & 6.5 & 5.7 & 5.7 & 5.7 \\ 404 & 2.0 \mathrm{e} 11 & 6 \mathrm{D} & -0.0001 & .67 / .68 & 1 / 1 & 6.7 & 6.5 & 6.5 & 5.9 & 5.9 & 5.9 \\ 405 & 2.0 \mathrm{e} 11 & 6 \mathrm{D} & 0.000 & .67 / .68 & 1 / 1 & 6.7 & 6.9 & 6.5 & 6.9 & 6.1 & 6.1 \\ 406 & 2.0 \mathrm{e} 11 & 6 \mathrm{D} & 0.0001 & .67 / .68 & 1 / 1 & 6.7 & 6.9 & 6.5 & 5.9 & 5.9 & 5.9 \\ 407 & 2.0 \mathrm{e} 11 & 6 \mathrm{D} & 0.0002 & .67 / .68 & 1 / 1 & 6.9 & 7.1 & 6.7 & 6.1 & 5.7 & 5.7 \\ 408 & 2.0 \mathrm{e} 11 & 6 \mathrm{D} & 0.0003 & .67 / .68 & 1 / 1 & 6.9 & 6.7 & 6.5 & 5.7 & 5.7 & 5.7 \\ 409 & 2.0 \mathrm{e} 11 & 6 \mathrm{D} & 0.0004 & .67 / .68 & 1 / 1 & 7.1 & 7.1 & 6.7 & 5.5 & 5.5 & 5.5 \\ 410 & 2.0 \mathrm{e} 11 & 6 \mathrm{D} & 0.0005 & .67 / .68 & 1 / 1 & 6.9 & 6.9 & 6.3 & 5.3 & 5.5 & 5.3\end{array}$

Scan $d p / p 0$ on top of PI phasers: Np=2.5e11

$\begin{array}{llllllllllll}13 & 2.5 \mathrm{e} 11 & 6 \mathrm{D} & -0.0005 & .67 / .68 & 1 / 1 & 6.1 & 5.7 & 6.3 & 4.7 & 4.5 & 4.5 \\ 14 & 2.5 \mathrm{e} 11 & 6 \mathrm{D} & -0.0004 & .67 / .68 & 1 / 1 & 6.1 & 5.9 & 5.7 & 5.7 & 4.5 & 4.5 \\ 15 & 2.5 \mathrm{e} 11 & 6 \mathrm{D} & -0.0003 & .67 / .68 & 1 / 1 & 6.7 & 6.1 & 6.1 & 5.5 & 4.7 & 4.7 \\ 16 & 2.5 \mathrm{e} 11 & 6 \mathrm{D} & -0.0002 & .67 / .68 & 1 / 1 & 6.3 & 6.7 & 5.9 & 5.3 & 5.9 & 5.3 \\ 17 & 2.5 \mathrm{e} 11 & 6 \mathrm{D} & -0.0001 & .67 / .68 & 1 / 1 & 6.5 & 6.5 & 6.3 & 5.7 & 6.3 & 5.7 \\ 18 & 2.5 \mathrm{e} 11 & 6 \mathrm{D} & 0.000 & .67 / .68 & 1 / 1 & 6.5 & 6.9 & 6.5 & 6.7 & 6.5 & 6.5 \\ 19 & 2.5 \mathrm{e} 11 & 6 \mathrm{D} & 0.0001 & .67 / .68 & 1 / 1 & 6.7 & 6.7 & 6.5 & 5.5 & 6.3 & 5.5 \\ 20 & 2.5 \mathrm{e} 11 & 6 \mathrm{D} & 0.0002 & .67 / .68 & 1 / 1 & 6.7 & 6.7 & 6.3 & 5.5 & 5.9 & 5.5 \\ 21 & 2.5 \mathrm{e} 11 & 6 \mathrm{D} & 0.0003 & .67 / .68 & 1 / 1 & 6.7 & 6.7 & 6.1 & 5.5 & 5.3 & 5.3 \\ 22 & 2.5 \mathrm{e} 11 & 6 \mathrm{D} & 0.0004 & .67 / .68 & 1 / 1 & 6.7 & 6.5 & 6.1 & 5.5 & 4.9 & 4.9 \\ 23 & 2.5 \mathrm{e} 11 & 6 \mathrm{D} & 0.0005 & .67 / .68 & 1 / 1 & 6.7 & 6.5 & 6.1 & 5.3 & 4.9 & 4.9\end{array}$

Scan $d p / p 0$ on top of PI phasers: $N p=3.0 e 11$

$\begin{array}{llllllllllll}411 & 3.0 \mathrm{e} 11 & 6 \mathrm{D} & -0.0005 & .67 / .68 & 1 / 1 & 5.5 & 5.3 & 4.9 & 4.7 & 4.7 & 4.7 \\ 412 & 3.0 \mathrm{e} 11 & 6 \mathrm{D} & -0.0004 & .67 / .68 & 1 / 1 & 5.9 & 5.7 & 5.1 & 4.5 & 3.8 & 3.8 \\ 413 & 3.0 \mathrm{e} 11 & 6 \mathrm{D} & -0.0003 & .67 / .68 & 1 / 1 & 5.7 & 6.1 & 6.3 & 4.9 & 4.1 & 4.1 \\ 414 & 3.0 \mathrm{e} 11 & 6 \mathrm{D} & -0.0002 & .67 / .68 & 1 / 1 & 5.7 & 5.9 & 5.7 & 4.9 & 4.1 & 4.1 \\ 415 & 3.0 \mathrm{e} 11 & 6 \mathrm{D} & -0.0001 & .67 / .68 & 1 / 1 & 6.3 & 5.9 & 5.7 & 5.5 & 6.3 & 5.5 \\ 416 & 3.0 \mathrm{e} 11 & 6 \mathrm{D} & 0.000 & .67 / .68 & 1 / 1 & 6.1 & 5.9 & 6.1 & 5.9 & 6.7 & 5.9 \\ 417 & 3.0 \mathrm{e} 11 & 6 \mathrm{D} & 0.0001 & .67 / .68 & 1 / 1 & 5.9 & 6.1 & 5.9 & 5.5 & 5.7 & 5.5 \\ 418 & 3.0 \mathrm{e} 11 & 6 \mathrm{D} & 0.0002 & .67 / .68 & 1 / 1 & 5.9 & 6.5 & 5.3 & 5.1 & 4.9 & 4.9 \\ 419 & 3.0 \mathrm{e} 11 & 6 \mathrm{D} & 0.0003 & .67 / .68 & 1 / 1 & 6.5 & 5.9 & 5.7 & 4.3 & 4.1 & 4.1 \\ 420 & 3.0 \mathrm{e} 11 & 6 \mathrm{D} & 0.0004 & .67 / .68 & 1 / 1 & 6.1 & 6.3 & 5.5 & 5.1 & 3.8 & 3.8 \\ 421 & 3.0 \mathrm{e} 11 & 6 \mathrm{D} & 0.0005 & .67 / .68 & 1 / 1 & 6.1 & 6.1 & 4.7 & 5.1 & 3.8 & 3.8\end{array}$

Scan $Q^{\prime}$ on top of PI phasers $\mathrm{Np}=2.0 \mathrm{e} 11$

\begin{tabular}{|c|c|c|c|c|c|c|c|c|c|c|c|}
\hline 422 & $2.0 \mathrm{e} 11$ & $6 \mathrm{D}$ & 0.0005 & $67 / .68$ & $-4 /-4$ & 6.5 & 6.7 & 5.9 & 5.1 & 5.3 & 5.1 \\
\hline 423 & $2.0 \mathrm{e} 11$ & $6 \mathrm{D}$ & 0.0005 & $.67 / .68$ & $-3 /-3$ & 6.7 & 6.7 & 6.3 & 5.3 & 5.5 & 5.3 \\
\hline 424 & $2.0 \mathrm{e} 11$ & $6 \mathrm{D}$ & 0.0005 & $.67 / .68$ & $-2 /-2$ & 6.9 & 6.3 & 6.1 & 5.3 & 5.9 & 5.3 \\
\hline 425 & $2.0 \mathrm{e} 11$ & $6 \mathrm{D}$ & 0.0005 & $.67 / .68$ & $-1 /-1$ & 6.7 & 6.5 & 6.1 & 5.1 & 5.5 & 5.1 \\
\hline 426 & $2.0 \mathrm{e} 11$ & $6 \mathrm{D}$ & 0.0005 & $.67 / .68$ & $0 / 0$ & 6.7 & 6.7 & 5.9 & 5.5 & 5.7 & 5.5 \\
\hline 427 & $2.0 \mathrm{e} 11$ & $6 \mathrm{D}$ & 0.0005 & $.67 / .68$ & $1 / 1$ & 6.9 & 6.9 & 6.3 & 5.3 & 5.5 & 5.3 \\
\hline 428 & $2.0 \mathrm{e} 11$ & $6 \mathrm{D}$ & 0.0005 & $.67 / .68$ & $2 / 2$ & 7.1 & 6.7 & 6.3 & 5.5 & 5.3 & 5.3 \\
\hline 429 & $2.0 \mathrm{e} 11$ & $6 \mathrm{D}$ & 0.0005 & $67 / .68$ & $3 / 3$ & 6.5 & 6.5 & 6.1 & 5.5 & 4.9 & 4.9 \\
\hline 430 & $2.0 \mathrm{e} 11$ & $6 \mathrm{D}$ & 0.0005 & $67 / .68$ & $4 / 4$ & 6.5 & 6.3 & 5.7 & 5.1 & 4.9 & 4.9 \\
\hline
\end{tabular}

Scan $Q^{\prime}$ on top of PI phasers $\mathrm{Np}=2.5 \mathrm{e} 11$

$\begin{array}{llllllllllll}24 & 2.5 \mathrm{e} 11 & 6 \mathrm{D} & 0.0005 & 67 / .68 & -4 /-4 & 6.7 & 6.5 & 5.9 & 5.5 & 4.7 & 4.7 \\ 25 & 2.5 \mathrm{e} 11 & 6 \mathrm{D} & 0.0005 & .67 / .68 & -3 /-3 & 6.7 & 6.7 & 6.3 & 4.9 & 4.5 & 4.5 \\ 26 & 2.5 \mathrm{e} 11 & 6 \mathrm{D} & 0.0005 & .67 / .68 & -2 /-2 & 6.3 & 6.7 & 6.3 & 5.7 & 4.5 & 4.5 \\ 27 & 2.5 \mathrm{e} 11 & 6 \mathrm{D} & 0.0005 & .67 / .68 & -1 /-1 & 6.5 & 6.9 & 6.3 & 5.3 & 4.5 & 4.5 \\ 28 & 2.5 \mathrm{e} 11 & 6 \mathrm{D} & 0.0005 & .67 / .68 & 0 / 0 & 6.7 & 6.5 & 6.3 & 5.3 & 4.9 & 4.9\end{array}$




$\begin{array}{llllllllllll}29 & 2.5 \mathrm{e} 11 & 6 \mathrm{D} & 0.0005 & .67 / .68 & 1 / 1 & 6.7 & 6.5 & 6.1 & 5.3 & 4.9 & 4.9 \\ 30 & 2.5 \mathrm{e} 11 & 6 \mathrm{D} & 0.0005 & .67 / .68 & 2 / 2 & 6.1 & 5.9 & 5.7 & 4.9 & 4.7 & 4.7 \\ 31 & 2.5 \mathrm{e} 11 & 6 \mathrm{D} & 0.0005 & 67 / .68 & 3 / 3 & 6.7 & 6.5 & 6.3 & 4.9 & 4.5 & 4.5 \\ 32 & 2.5 \mathrm{e} 11 & 6 \mathrm{D} & 0.0003 & 67 / .68 & 4 / 4 & 6.1 & 6.1 & 5.7 & 5.1 & 4.5 & 4.5\end{array}$

Scan Q' on top of PI phasers $\mathrm{Np}=3.0 \mathrm{e} 11$

\begin{tabular}{|c|c|c|c|c|c|c|c|c|c|c|}
\hline 431 & $3.0 \mathrm{e} 11$ & $6 \mathrm{D}$ & 0.0005 & $67 / .68$ & $-4 /-4$ & 5.9 & 6.3 & 5.7 & 4.7 & 4.1 \\
\hline 432 & $3.0 \mathrm{e} 11$ & $6 \mathrm{D}$ & 0.0005 & $.67 / .68$ & $-3 /-3$ & 5.9 & 5.3 & 5.5 & 4.5 & 3.8 \\
\hline 433 & $3.0 \mathrm{e} 11$ & $6 \mathrm{D}$ & 0.0005 & $.67 / .68$ & $-2 /-2$ & 5.9 & 5.9 & 5.3 & 4.7 & 3.8 \\
\hline 434 & 3. $0 \mathrm{e} 11$ & $6 \mathrm{D}$ & 0.0005 & $.67 / .68$ & $-1 /-1$ & 5.9 & 6.3 & 5.3 & 4.5 & 4.1 \\
\hline 435 & $3.0 \mathrm{e} 11$ & $6 \mathrm{D}$ & 0.0005 & $.67 / .68$ & $0 / 0$ & 5.9 & 6.7 & 6.1 & 4.1 & 4.7 \\
\hline 436 & $3.0 \mathrm{e} 11$ & $6 \mathrm{D}$ & 0.0005 & $.67 / .68$ & $1 / 1$ & 6.1 & 6.1 & 4.7 & 5.1 & 3.8 \\
\hline 437 & $3.0 \mathrm{e} 11$ & $6 \mathrm{D}$ & 0.0005 & $.67 / .68$ & $2 / 2$ & 5.9 & 5.7 & 4.9 & 4.7 & 4.1 \\
\hline 438 & $3.0 \mathrm{e} 11$ & $6 \mathrm{D}$ & 0.0005 & $67 / .68$ & $3 / 3$ & 5.7 & 5.3 & 5.3 & 4.3 & 3.8 \\
\hline 439 & 3. $0 \mathrm{e} 11$ & $6 \mathrm{D}$ & 0.0003 & $67 / .68$ & $4 / 4$ & 5.3 & 6.3 & 5.3 & 4.9 & 4.1 \\
\hline
\end{tabular}

Q' correction on top of PI phasers

$\begin{array}{lllllllllllll}33 & 2.0 \mathrm{e} 11 & 6 \mathrm{D} & 0.000 & 67 / .68 & 1 / 1 & 8.3 & 6.9 & 6.7 & 6.9 & 6.1 & 6.1 \\ 34 & 2.5 \mathrm{e} 11 & 6 \mathrm{D} & 0.000 & .67 / .68 & 1 / 1 & 6.9 & 6.7 & 6.3 & 7.1 & 7.5 & 6.3 \\ 35 & 3.0 \mathrm{e} 11 & 6 \mathrm{D} & 0.000 & .67 / .68 & 1 / 1 & 6.1 & 5.9 & 5.9 & 6.1 & 6.9 & 5.9 \\ & & & & & & & & & & & & \\ 36 & 2.0 \mathrm{e} 11 & 6 \mathrm{D} & 0.0005 & 67 / .68 & 1 / 1 & 6.7 & 6.7 & 6.1 & 5.7 & 5.5 & 5.5 \\ 37 & 2.5 \mathrm{e} 11 & 6 \mathrm{D} & 0.0005 & .67 / .68 & 1 / 1 & 6.5 & 6.5 & 6.3 & 5.3 & 4.5 & 4.5 \\ 38 & 3.0 \mathrm{e} 11 & 6 \mathrm{D} & 0.0005 & .67 / .68 & 1 / 1 & 6.5 & 6.3 & 6.1 & 4.5 & 3.8 & 3.8\end{array}$

Scan of phase shift away from PI phasers, $N p=2.5 \mathrm{e} 11$

\begin{tabular}{lllllllllllll} 
& & & \multicolumn{7}{c}{ Mfront (degree) } & & \\
101 & $2.5 \mathrm{e} 11$ & $6 \mathrm{D}$ & 0.0005 & $67 / .68$ & $1 / 1$ & $20+$ & 6.1 & 6.3 & 6.1 & 5.1 & 4.7 & 4.7 \\
102 & $2.5 \mathrm{e} 11$ & $6 \mathrm{D}$ & 0.0005 & $.67 / .68$ & $1 / 1$ & $15+$ & 6.5 & 6.5 & 6.3 & 5.3 & 4.5 & 4.5 \\
103 & $2.5 \mathrm{e} 11$ & $6 \mathrm{D}$ & 0.0005 & $.67 / .68$ & $1 / 1$ & $10+$ & 6.3 & 6.7 & 6.1 & 6.3 & 4.7 & 4.7 \\
104 & $2.5 \mathrm{e} 11$ & $6 \mathrm{D}$ & 0.0005 & $67 / .68$ & $1 / 1$ & $5+$ & 6.3 & 6.7 & 6.1 & 5.5 & 4.5 & 4.5 \\
105 & $2.5 \mathrm{e} 11$ & $6 \mathrm{D}$ & 0.0005 & $.67 / .68$ & $1 / 1$ & $2.5+$ & 6.5 & 6.5 & 6.3 & 5.5 & 4.7 & 4.7 \\
106 & $2.5 \mathrm{e} 11$ & $6 \mathrm{D}$ & 0.0005 & $.67 / .68$ & $1 / 1$ & 0 & 7.1 & 6.3 & 6.7 & 5.3 & 4.7 & 4.7 \\
107 & $2.5 \mathrm{e} 11$ & $6 \mathrm{D}$ & 0.0005 & $67 / .68$ & $1 / 1$ & -2.5 & 6.3 & 6.1 & 6.3 & 5.5 & 4.7 & 4.7 \\
108 & $2.5 \mathrm{e} 11$ & $6 \mathrm{D}$ & 0.0005 & $.67 / .68$ & $1 / 1$ & -5 & 7.1 & 6.5 & 6.1 & 6.3 & 4.7 & 4.7 \\
109 & $2.5 \mathrm{e} 11$ & $6 \mathrm{D}$ & 0.0005 & $.67 / .68$ & $1 / 1$ & -10 & 6.7 & 6.3 & 6.3 & 5.5 & 4.7 & 4.7 \\
110 & $2.5 \mathrm{e} 11$ & $6 \mathrm{D}$ & 0.0005 & $67 / .68$ & $1 / 1$ & -15 & 6.7 & 6.5 & 5.7 & 5.7 & 5.7 & 5.7 \\
111 & $2.5 \mathrm{e} 11$ & $6 \mathrm{D}$ & 0.0005 & $.67 / .68$ & $1 / 1$ & -20 & 6.7 & 6.3 & 5.9 & 5.9 & 5.7 & 5.7
\end{tabular}

Scan of phase shift away from PI phasers, Np=2.0e11

$\begin{array}{lllllllllllll}440 & 2.0 \mathrm{e} 11 & 6 \mathrm{D} & 0.0005 & 67 / .68 & 1 / 1 & 15.0+ & 6.7 & 6.5 & 6.1 & 5.1 & 5.1 & 5.1 \\ 441 & 2.0 \mathrm{e} 11 & 6 \mathrm{D} & 0.0005 & .67 / .68 & 1 / 1 & 10.0+ & 6.9 & 6.9 & 6.3 & 5.5 & 5.3 & 5.3 \\ 442 & 2.0 \mathrm{e} 11 & 6 \mathrm{D} & 0.0005 & .67 / .68 & 1 / 1 & 5.0+ & 6.9 & 7.1 & 6.3 & 5.7 & 5.3 & 5.3 \\ 443 & 2.0 \mathrm{e} 11 & 6 \mathrm{D} & 0.0005 & 67 / .68 & 1 / 1 & 2.5+ & 7.1 & 6.7 & 6.3 & 6.1 & 5.3 & 5.3 \\ 444 & 2.0 \mathrm{e} 11 & 6 \mathrm{D} & 0.0005 & .67 / .68 & 1 / 1 & 2.0+ & 6.7 & 6.7 & 6.3 & 5.7 & 5.3 & 5.3 \\ 445 & 2.0 \mathrm{e} 11 & 6 \mathrm{D} & 0.0005 & .67 / .68 & 1 / 1 & 1.5+ & 7.1 & 6.7 & 6.3 & 5.9 & 5.5 & 5.5 \\ 446 & 2.0 \mathrm{e} 11 & 6 \mathrm{D} & 0.0005 & 67 / .68 & 1 / 1 & 1.0 & 6.9 & 7.1 & 6.1 & 5.9 & 5.3 & 5.3 \\ 447 & 2.0 \mathrm{e} 11 & 6 \mathrm{D} & 0.0005 & .67 / .68 & 1 / 1 & .5+ & 6.7 & 6.9 & 6.5 & 5.3 & 5.5 & 5.3 \\ 448 & 2.0 \mathrm{e} 11 & 6 \mathrm{D} & 0.0005 & .67 / .68 & 1 / 1 & 0 & 6.5 & 6.5 & 6.3 & 5.5 & 5.5 & 5.5 \\ 449 & 2.0 \mathrm{e} 11 & 6 \mathrm{D} & 0.0005 & 67 / .68 & 1 / 1 & -0.5 & 6.5 & 6.5 & 6.3 & 5.9 & 5.7 & 5.7 \\ 450 & 2.0 \mathrm{e} 11 & 6 \mathrm{D} & 0.0005 & .67 / .68 & 1 / 1 & -1.0 & 6.7 & 6.5 & 6.5 & 5.3 & 5.3 & 5.3 \\ 451 & 2.0 \mathrm{e} 11 & 6 \mathrm{D} & 0.0005 & .67 / .68 & 1 / 1 & -1.5 & 6.7 & 6.5 & 6.3 & 5.7 & 5.1 & 5.1 \\ 452 & 2.0 \mathrm{e} 11 & 6 \mathrm{D} & 0.0005 & 67 / .68 & 1 / 1 & -2.0 & 6.7 & 6.5 & 6.5 & 5.9 & 5.3 & 5.3 \\ 453 & 2.0 \mathrm{e} 11 & 6 \mathrm{D} & 0.0005 & .67 / .68 & 1 / 1 & -2.5 & 6.9 & 7.1 & 6.1 & 5.7 & 5.5 & 5.5\end{array}$




\begin{tabular}{|c|c|c|c|c|c|c|c|c|c|c|c|c|}
\hline 454 & $2.0 \mathrm{e} 11$ & $6 \mathrm{D}$ & 0.0005 & $.67 / .68$ & $1 / 1$ & -5.0 & 6.5 & 6.1 & 6.1 & 5.5 & 5.5 & 5.5 \\
\hline 455 & $2.0 \mathrm{e} 11$ & $6 \mathrm{D}$ & 0.0005 & $.67 / .68$ & $1 / 1$ & -10.0 & 6.5 & 6.5 & 5.9 & 5.3 & 5.3 & 5.3 \\
\hline 56 & $2.0 \mathrm{e} 11$ & $6 \mathrm{D}$ & 0.0005 & $.67 / .68$ & $1 / 1$ & -15.0 & 6.3 & 6.3 & 5.7 & 5.3 & 5.3 & 5.3 \\
\hline
\end{tabular}

Scan of phase shift away from PI phasers, $\mathrm{Np}=2.5 \mathrm{e} 11$

\begin{tabular}{|c|c|c|c|c|c|c|c|c|c|c|c|}
\hline $2.5 e 11$ & $6 \mathrm{D}$ & 0.0005 & $.67 / .68$ & $1 / 1$ & $15+$ & 6.5 & 6.5 & 6.3 & 5.3 & 4.5 & 4.5 \\
\hline $2.5 e 11$ & $6 \mathrm{D}$ & 0.0005 & $.67 / .68$ & $1 / 1$ & $10+$ & 6.3 & 6.7 & 6.1 & 6.3 & 4.7 & 4.7 \\
\hline $2.5 \mathrm{e} 11$ & $6 \mathrm{D}$ & 0.0005 & $67 / .68$ & $1 / 1$ & $5+$ & 6.3 & 6.7 & 6.1 & 5.5 & 4.5 & 4.5 \\
\hline $2.5 \mathrm{e} 11$ & $6 \mathrm{D}$ & 0.0005 & $67 / .68$ & $1 / 1$ & $2.5+$ & 6.5 & 6.5 & 6.3 & 5.5 & 4.7 & 4.7 \\
\hline $2.5 e 11$ & $6 \mathrm{D}$ & 0.0005 & $.67 / .68$ & $1 / 1$ & $2.0+$ & 6.5 & 6.5 & 6.1 & 5.5 & 4.5 & 4.5 \\
\hline $2.5 \mathrm{e} 11$ & $6 \mathrm{D}$ & 0.0005 & $.67 / .68$ & $1 / 1$ & $1.5+$ & 6.5 & 6.5 & 6.1 & 5.9 & 4.7 & 4.7 \\
\hline $2.5 e 11$ & $6 \mathrm{D}$ & 0.0005 & $67 / .68$ & $1 / 1$ & 1.0 & 6.5 & 6.5 & 6.1 & 5.3 & 4.7 & 4.7 \\
\hline $2.5 \mathrm{e} 11$ & $6 \mathrm{D}$ & 0.0005 & $.67 / .68$ & $1 / 1$ & $.5+$ & 6.5 & 6.5 & 6.3 & 5.5 & 4.7 & 4.7 \\
\hline $2.5 \mathrm{e} 11$ & $6 \mathrm{D}$ & 0.0005 & $.67 / .68$ & $1 / 1$ & 0 & 7.1 & 6.3 & 6.7 & 5.3 & 4.7 & 4.7 \\
\hline $2.5 \mathrm{e} 11$ & $6 \mathrm{D}$ & 0.0005 & $67 / .68$ & $1 / 1$ & -0.5 & 6.5 & 6.3 & 5.9 & 5.3 & 4.7 & 4.7 \\
\hline $2.5 e 11$ & $6 \mathrm{D}$ & 0.0005 & $.67 / .68$ & $1 / 1$ & -1.0 & 6.5 & 6.3 & 5.7 & 4.9 & 4.9 & 4.9 \\
\hline $2.5 \mathrm{e} 11$ & $6 \mathrm{D}$ & 0.0005 & $.67 / .68$ & $1 / 1$ & -1.5 & 6.5 & 6.5 & 6.3 & 5.3 & 4.7 & 4.7 \\
\hline $2.5 e 11$ & $6 \mathrm{D}$ & 0.0005 & $67 / .68$ & $1 / 1$ & -2.0 & 6.7 & 6.5 & 6.3 & 4.9 & 4.5 & 4.5 \\
\hline $2.5 \mathrm{e} 11$ & $6 \mathrm{D}$ & 0.0005 & $.67 / .68$ & $1 / 1$ & -2.5 & 6.3 & 6.1 & 6.3 & 5.5 & 4.7 & 4.7 \\
\hline $2.5 \mathrm{e} 11$ & $6 \mathrm{D}$ & 0.0005 & $.67 / .68$ & $1 / 1$ & -5 & 7.1 & 6.5 & 6.1 & 6.3 & 4.7 & 4.7 \\
\hline $2.5 e 11$ & $6 \mathrm{D}$ & 0.0005 & $.67 / .68$ & $1 / 1$ & -10 & 6.7 & 6.3 & 6.3 & 5.5 & 4.7 & 4.7 \\
\hline $2.5 \mathrm{e} 11$ & $6 \mathrm{D}$ & 0.0005 & $67 / .68$ & $1 / 1$ & -15 & 6.7 & 6.5 & 5.7 & 5.7 & 5.7 & 5.7 \\
\hline
\end{tabular}

Scan of phase shift away from PI phasers, $\mathrm{Np}=3.0 \mathrm{e} 11$

\begin{tabular}{|c|c|c|c|c|c|c|c|c|c|c|c|c|}
\hline 457 & 3. 0e11 & $6 \mathrm{D}$ & 0.0005 & $67 / .68$ & $1 / 1$ & $15.0+$ & 5.9 & 5.9 & 5.7 & 5.3 & 4.9 & 4.9 \\
\hline 458 & $3.0 \mathrm{e} 11$ & $6 \mathrm{D}$ & 0.0005 & $.67 / .68$ & $1 / 1$ & $10.0+$ & 6.1 & 5.9 & 5.3 & 5.5 & 4.3 & 4.3 \\
\hline 459 & $3.0 \mathrm{e} 11$ & $6 \mathrm{D}$ & 0.0005 & $.67 / .68$ & $1 / 1$ & $5.0+$ & 5.7 & 6.1 & 5.9 & 4.3 & 4.0 & 4.0 \\
\hline 460 & $3.0 \mathrm{e} 11$ & $6 \mathrm{D}$ & 0.0005 & $67 / .68$ & $1 / 1$ & $3.0+$ & 5.7 & 6.3 & 5.7 & 4.5 & 4.0 & 4.0 \\
\hline 461 & $3.0 \mathrm{e} 11$ & $6 \mathrm{D}$ & 0.0005 & $.67 / .68$ & $1 / 1$ & $2.0+$ & 6.3 & 6.5 & 5.3 & 4.3 & 3.8 & 3.8 \\
\hline 462 & $3.0 \mathrm{e} 11$ & $6 \mathrm{D}$ & 0.0005 & $.67 / .68$ & $1 / 1$ & $1.5+$ & 6.3 & 6.1 & 5.9 & 4.5 & 3.8 & 3.8 \\
\hline 463 & $3.0 \mathrm{e} 11$ & $6 \mathrm{D}$ & 0.0005 & $67 / .68$ & $1 / 1$ & 1.0 & 6.3 & 5.9 & 5.5 & 4.3 & 4.0 & 4.0 \\
\hline 464 & 3. 0e11 & $6 \mathrm{D}$ & 0.0005 & $.67 / .68$ & $1 / 1$ & $.5+$ & 6.3 & 5.7 & 5.9 & 4.5 & 3.8 & 3.8 \\
\hline 465 & $3.0 \mathrm{e} 11$ & $6 \mathrm{D}$ & 0.0005 & $.67 / .68$ & $1 / 1$ & 0 & 6.3 & 6.5 & 6.1 & 4.5 & 3.8 & 3.8 \\
\hline 466 & $3.0 \mathrm{e} 11$ & $6 \mathrm{D}$ & 0.0005 & $67 / .68$ & $1 / 1$ & -0.5 & 5.7 & 6.3 & 5.9 & 4.5 & 3.8 & 3.8 \\
\hline 467 & $3.0 e 11$ & $6 \mathrm{D}$ & 0.0005 & $.67 / .68$ & $1 / 1$ & -1.0 & 6.3 & 5.7 & 5.7 & 4.7 & 4.0 & 4.0 \\
\hline 468 & 3. $0 \mathrm{e} 11$ & $6 \mathrm{D}$ & 0.0005 & $.67 / .68$ & $1 / 1$ & -1.5 & 6.1 & 6.3 & 5.5 & 4.7 & 5.5 & 4.7 \\
\hline 469 & $3.0 \mathrm{e} 11$ & $6 \mathrm{D}$ & 0.0005 & $67 / .68$ & $1 / 1$ & -2.0 & 6.5 & 5.7 & 5.7 & 5.1 & 4.0 & 4.0 \\
\hline 470 & $3.0 \mathrm{e} 11$ & $6 \mathrm{D}$ & 0.0005 & $.67 / .68$ & $1 / 1$ & -2.5 & 6.1 & 5.7 & 5.9 & 4.5 & 4.0 & 4.0 \\
\hline 471 & 3. $0 \mathrm{e} 11$ & $6 \mathrm{D}$ & 0.0005 & $.67 / .68$ & $1 / 1$ & -5.0 & 5.7 & 5.9 & 5.3 & 5.1 & 4.7 & 4.7 \\
\hline 472 & $3.0 \mathrm{e} 11$ & $6 \mathrm{D}$ & 0.0005 & $.67 / .68$ & $1 / 1$ & -10.0 & 6.3 & 6.3 & 5.3 & 5.1 & 3.8 & 3.8 \\
\hline 473 & $3.0 \mathrm{e} 11$ & $6 \mathrm{D}$ & 0.0005 & $.67 / .68$ & $1 / 1$ & -15.0 & 5.9 & 5.9 & 5.5 & 5.1 & 5.9 & 5.1 \\
\hline
\end{tabular}

scan $\mathrm{Ne}$ (compensation strength), with Q' correction, Q'=1, PI phasers

\begin{tabular}{|c|c|c|c|c|c|c|c|c|c|c|c|}
\hline 123 & $2.0 \mathrm{e} 11$ & $0.5 \mathrm{e} 116 \mathrm{D}$ & 0.0005 & $67 / .68$ & $1 / 1$ & 7.1 & 6.7 & 5.9 & 5.3 & 5.1 & 5.1 \\
\hline 124 & $2.0 \mathrm{e} 11$ & $1.0 \mathrm{e} 116 \mathrm{D}$ & 0.0005 & $67 / .68$ & $1 / 1$ & 6.9 & 6.5 & 5.9 & 6.1 & 4.1 & 4.1 \\
\hline 125 & $2.0 \mathrm{e} 11$ & $1.5 \mathrm{e} 116 \mathrm{D}$ & 0.0005 & $67 / .68$ & $1 / 1$ & 7.1 & 7.1 & 7.1 & 5.9 & 5.5 & 5.5 \\
\hline 126 & $2.0 \mathrm{e} 11$ & $2.0 \mathrm{e} 116 \mathrm{D}$ & 0.0005 & $67 / .68$ & $1 / 1$ & 6.7 & 6.7 & 6.1 & 5.7 & 5.5 & 5.5 \\
\hline 127 & $2.0 \mathrm{e} 11$ & $2.5 \mathrm{e} 116 \mathrm{D}$ & 0.0005 & $67 / .68$ & $1 / 1$ & 6.1 & 6.3 & 5.5 & 5.7 & 5.1 & 5.1 \\
\hline 128 & $2.0 \mathrm{e} 11$ & $3.0 \mathrm{e} 116 \mathrm{D}$ & 0.0005 & $67 / .68$ & $1 / 1$ & 5.5 & 5.1 & 4.3 & 4.0 & 5.3 & 4.0 \\
\hline 129 & $2.0 \mathrm{e} 11$ & $3.5 \mathrm{e} 116 \mathrm{D}$ & 0.0005 & $67 / .68$ & $1 / 1$ & 4.1 & 3.4 & 3.0 & 2.8 & 5.1 & 2.8 \\
\hline 130 & $2.0 \mathrm{e} 11$ & $4.0 \mathrm{e} 116 \mathrm{D}$ & 0.0005 & $67 / .68$ & $1 / 1$ & 1.4 & 1.4 & 1.6 & 2.4 & 3.8 & 1.4 \\
\hline 131 & $2.5 \mathrm{e} 11$ & $0.5 \mathrm{e} 116 \mathrm{D}$ & 0.0005 & $67 / .68$ & $1 / 1$ & 5.5 & 6.3 & 4.9 & 4.7 & 4.9 & 4.7 \\
\hline 132 & $2.5 \mathrm{e} 11$ & $1.0 \mathrm{e} 116 \mathrm{D}$ & 0.0005 & $67 / .68$ & $1 / 1$ & 6.3 & 5.7 & 5.1 & 5.5 & 5.5 & 5.1 \\
\hline 133 & $2.5 e 11$ & $1.5 \mathrm{e} 116 \mathrm{D}$ & 0.0005 & $67 / .68$ & $1 / 1$ & 5.3 & 5.9 & 5.3 & 5.5 & 4.5 & 4.5 \\
\hline 134 & $2.5 e 11$ & $2.0 \mathrm{e} 116 \mathrm{D}$ & 0.0005 & $67 / .68$ & $1 / 1$ & 6.5 & 6.3 & 6.1 & 4.5 & 4.1 & 4.1 \\
\hline 135 & $2.5 e 11$ & $2.5 \mathrm{e} 116 \mathrm{D}$ & 0.0005 & $67 / .68$ & $1 / 1$ & 6.5 & 6.5 & 6.3 & 5.3 & 4.5 & 4.5 \\
\hline
\end{tabular}




\begin{tabular}{|c|c|c|c|c|c|c|c|c|c|c|c|c|}
\hline 136 & $2.5 e 11$ & $3.0 \mathrm{e} 11$ & $6 \mathrm{D}$ & 0.0005 & $67 / .68$ & $1 / 1$ & 6.3 & 6.1 & 6.3 & 5.7 & 5.3 & 5.3 \\
\hline 137 & $2.5 \mathrm{e} 11$ & $3.5 \mathrm{e} 11$ & $6 \mathrm{D}$ & 0.0005 & $67 / .68$ & $1 / 1$ & 5.9 & 5.3 & 4.9 & 4.9 & 4.5 & 4.5 \\
\hline 138 & $2.5 \mathrm{e} 11$ & $4.0 \mathrm{e} 11$ & $6 \mathrm{D}$ & 0.0005 & $67 / .68$ & $1 / 1$ & 4.9 & 4.7 & 4.0 & 3.0 & 3.0 & 3.0 \\
\hline 139 & $2.5 \mathrm{e} 11$ & $4.5 \mathrm{e} 11$ & $6 \mathrm{D}$ & 0.0005 & $67 / .68$ & $1 / 1$ & 2.2 & 2.0 & 1.6 & 1.4 & 4.7 & 1.4 \\
\hline 140 & $2.5 \mathrm{e} 11$ & $5.0 \mathrm{e} 11$ & $6 \mathrm{D}$ & 0.0005 & $67 / .68$ & $1 / 1$ & 1.2 & 1.2 & 1.4 & 2.0 & 3.2 & 1.2 \\
\hline 141 & $3.0 \mathrm{e} 11$ & $0.5 e 11$ & $6 \mathrm{D}$ & 0.0005 & $67 / .68$ & $1 / 1$ & 6.3 & 4.9 & 3.8 & 3.0 & 3.8 & 3.0 \\
\hline 142 & $3.0 \mathrm{e} 11$ & $1.0 \mathrm{e} 11$ & $6 \mathrm{D}$ & 0.0005 & $67 / .68$ & $1 / 1$ & 4.5 & 4.5 & 4.0 & 4.3 & 3.4 & 3.4 \\
\hline 143 & $3.0 \mathrm{e} 11$ & $1.5 \mathrm{e} 11$ & $6 \mathrm{D}$ & 0.0005 & $67 / .68$ & $1 / 1$ & 5.3 & 4.9 & 4.1 & 4.0 & 4.0 & 4.0 \\
\hline 144 & $3.0 \mathrm{e} 11$ & $2.0 \mathrm{e} 11$ & $6 \mathrm{D}$ & 0.0005 & $67 / .68$ & $1 / 1$ & 5.3 & 5.5 & 4.7 & 4.3 & 4.5 & 4.3 \\
\hline 145 & $3.0 \mathrm{e} 11$ & $2.5 e 11$ & $6 \mathrm{D}$ & 0.0005 & $67 / .68$ & $1 / 1$ & 5.7 & 6.3 & 5.5 & 4.7 & 4.3 & 4.3 \\
\hline 146 & $3.0 \mathrm{e} 11$ & $3.0 \mathrm{e} 11$ & $6 \mathrm{D}$ & 0.0005 & $67 / .68$ & $1 / 1$ & 6.5 & 6.3 & 6.1 & 4.5 & 3.8 & 3.8 \\
\hline 147 & $3.0 \mathrm{e} 11$ & $3.5 \mathrm{e} 11$ & $6 \mathrm{D}$ & 0.0005 & $67 / .68$ & $1 / 1$ & 6.1 & 6.1 & 5.9 & 5.5 & 4.3 & 4.3 \\
\hline 148 & $3.0 \mathrm{e} 11$ & $4.0 \mathrm{e} 11$ & $6 \mathrm{D}$ & 0.0005 & $67 / .68$ & $1 / 1$ & 5.7 & 5.9 & 5.5 & 4.7 & 5.1 & 4.7 \\
\hline 149 & $3.0 \mathrm{e} 11$ & $4.5 e 11$ & $6 \mathrm{D}$ & 0.0005 & $67 / .68$ & $1 / 1$ & 5.3 & 4.7 & 4.7 & 4.1 & 4.1 & 4.1 \\
\hline 150 & $3.0 \mathrm{e} 11$ & $5.0 e 11$ & $6 \mathrm{D}$ & 0.0005 & $67 / .68$ & $1 / 1$ & 3.8 & 3.8 & 3.4 & 2.8 & 2.4 & 2.4 \\
\hline 151 & $3.0 \mathrm{e} 11$ & $5.5 e 11$ & $6 \mathrm{D}$ & 0.0005 & $67 / .68$ & $1 / 1$ & 1.4 & 1.2 & 0.8 & 0.6 & 3.8 & 0.6 \\
\hline 152 & $3.0 \mathrm{e} 11$ & $6.0 \mathrm{e} 11$ & $6 \mathrm{D}$ & 0.0005 & $67 / .68$ & $1 / 1$ & 0.0 & 0.0 & 0.0 & 0.2 & 0.2 & 0.0 \\
\hline
\end{tabular}

scan electron beam size: (copy from workshop126 ) with Q', correction, with PI phaser,

\begin{tabular}{|c|c|c|c|c|c|c|c|c|c|c|c|c|}
\hline & & & & & \multicolumn{8}{|c|}{ factor $($ sigma_e $=$ factor $*$ sigma_p $)$} \\
\hline 175 & $2.0 \mathrm{e} 11$ & $6 \mathrm{D}$ & 0.0005 & $.67 / .68$ & $1 / 1$ & 0.6 & 0.0 & 0.0 & 0.0 & 0.0 & 0.0 & 0.0 \\
\hline 176 & $2.0 \mathrm{e} 11$ & $6 \mathrm{D}$ & 0.0005 & $.67 / .68$ & $1 / 1$ & 0.8 & 4.7 & 4.7 & 3.4 & 4.1 & 5.1 & 3.4 \\
\hline 177 & $2.0 \mathrm{e} 11$ & $6 \mathrm{D}$ & 0.0005 & $.67 / .68$ & $1 / 1$ & 1.0 & 6.7 & 6.7 & 6.1 & 5.7 & 5.5 & 5.5 \\
\hline 178 & $2.0 \mathrm{e} 11$ & $6 \mathrm{D}$ & 0.0005 & $.67 / .68$ & $1 / 1$ & 1.2 & 7.1 & 7.1 & 6.9 & 5.7 & 5.3 & 5.3 \\
\hline 179 & $2.0 \mathrm{e} 11$ & $6 \mathrm{D}$ & 0.0005 & $.67 / .68$ & $1 / 1$ & 1.4 & 7.9 & 7.1 & 6.1 & 6.5 & 5.3 & 5.3 \\
\hline 180 & $2.0 \mathrm{e} 11$ & $6 \mathrm{D}$ & 0.0005 & $.67 / .68$ & $1 / 1$ & 1.6 & 7.3 & 6.9 & 6.1 & 5.9 & 5.3 & 5.3 \\
\hline 181 & $2.0 \mathrm{e} 11$ & $6 \mathrm{D}$ & 0.0005 & $.67 / .68$ & $1 / 1$ & 1.8 & 6.9 & 6.7 & 6.7 & 6.3 & 5.5 & 5.5 \\
\hline 182 & $2.0 \mathrm{e} 11$ & $6 \mathrm{D}$ & 0.0005 & $.67 / .68$ & $1 / 1$ & 2.0 & 7.3 & 7.1 & 6.9 & 5.5 & 5.7 & 5.5 \\
\hline 183 & $2.5 \mathrm{e} 11$ & $6 \mathrm{D}$ & 0.0005 & $.67 / .68$ & $1 / 1$ & 0.6 & 0.0 & 0.0 & 0.0 & 0.0 & 0.0 & 0.0 \\
\hline 184 & $2.5 \mathrm{e} 11$ & $6 \mathrm{D}$ & 0.0005 & $.67 / .68$ & $1 /$ & 0.8 & 4.7 & 4.0 & 3.4 & 3.2 & 5.1 & 3.2 \\
\hline 185 & $2.5 \mathrm{e} 11$ & $6 \mathrm{D}$ & 0.0005 & $.67 / .68$ & $1 / 1$ & 1.0 & 6.5 & 6.5 & 6.3 & 5.3 & 4.5 & 4.5 \\
\hline 186 & $2.5 e 11$ & $6 \mathrm{D}$ & 0.0005 & $.67 / .68$ & $1 / 1$ & 1.2 & 6.5 & 6.5 & 5.9 & 5.7 & 5.5 & 5.5 \\
\hline 187 & $2.5 e 11$ & $6 \mathrm{D}$ & 0.0005 & $.67 / .68$ & $1 / 1$ & 1.4 & 6.3 & 6.7 & 6.3 & 5.3 & 5.5 & 5.3 \\
\hline 188 & $2.5 e 11$ & $6 \mathrm{D}$ & 0.0005 & $.67 / .68$ & $1 / 1$ & 1.6 & 6.5 & 6.7 & 5.3 & 4.5 & 4.7 & 4.5 \\
\hline 189 & $2.5 \mathrm{e} 11$ & $6 \mathrm{D}$ & 0.0005 & $.67 / .68$ & $1 / 1$ & 1.8 & 5.9 & 5.5 & 5.3 & 4.5 & 5.9 & 4.5 \\
\hline 190 & $2.5 \mathrm{e} 11$ & $6 \mathrm{D}$ & 0.0005 & $.67 / .68$ & $1 /$ & 2.0 & 5.9 & 6.3 & 4.5 & 4.7 & 5.7 & 4.5 \\
\hline 191 & $3.0 \mathrm{e} 11$ & $6 \mathrm{D}$ & 0.0005 & $.67 / .68$ & $1 / 1$ & 0.6 & 0.0 & 0.0 & 0.0 & 0.0 & 0.0 & 0.0 \\
\hline 192 & $3.0 \mathrm{e} 11$ & $6 \mathrm{D}$ & 0.0005 & $.67 / .68$ & $1 / 1$ & 0.8 & 4.7 & 4.1 & 3.8 & 2.8 & 4.5 & 2.8 \\
\hline 193 & $3.0 \mathrm{e} 11$ & $6 \mathrm{D}$ & 0.0005 & $.67 / .68$ & $1 / 1$ & 1.0 & 5.5 & 6.3 & 5.3 & 4.5 & 4.0 & 4.0 \\
\hline 194 & $3.0 \mathrm{e} 11$ & $6 \mathrm{D}$ & 0.0005 & $.67 / .68$ & $1 / 1$ & 1.2 & 5.9 & 5.7 & 4.9 & 4.7 & 4.5 & 4.5 \\
\hline 195 & $3.0 \mathrm{e} 11$ & $6 \mathrm{D}$ & 0.0005 & $.67 / .68$ & $1 / 1$ & 1.4 & 5.5 & 5.5 & 4.7 & 4.5 & 3.6 & 3.6 \\
\hline 196 & $3.0 \mathrm{e} 11$ & $6 \mathrm{D}$ & 0.0005 & $.67 / .68$ & $1 / 1$ & 1.6 & 4.5 & 4.5 & 4.0 & 3.6 & 3.6 & 3.6 \\
\hline 197 & $3.0 \mathrm{e} 11$ & $6 \mathrm{D}$ & 0.0005 & $.67 / .68$ & $1 /$ & 1.8 & 5.7 & 4.9 & 3.8 & 4.1 & 6.3 & 3.8 \\
\hline 198 & $3.0 \mathrm{e} 11$ & $6 \mathrm{D}$ & 0.0005 & $.67 / .68$ & $1 / 1$ & 2.0 & 6.3 & 5.5 & 3.4 & 3.8 & 6.3 & 3.4 \\
\hline
\end{tabular}

scan proton-electron $X / Y$ offset: ( from 0 to SEPMAX), with Q', correction, with PI phaser

\begin{tabular}{|c|c|c|c|c|c|c|c|c|c|c|c|c|}
\hline \multirow[b]{2}{*}{199} & \multirow[b]{2}{*}{$2.0 \mathrm{e} 11$} & \multirow[b]{2}{*}{$6 \mathrm{D}$} & \multirow[b]{2}{*}{0.0005} & \multirow[b]{2}{*}{$.67 / .68$} & \multicolumn{4}{|c|}{ offset [sigma] } & \multirow[b]{2}{*}{6.3} & \multirow[b]{2}{*}{5.9} & \multirow[b]{2}{*}{5.3} & \multirow[b]{2}{*}{5.3} \\
\hline & & & & & $1 / 1$ & 0.2 & 6.5 & 6.7 & & & & \\
\hline 200 & $2.0 \mathrm{e} 11$ & $6 \mathrm{D}$ & 0.0005 & $.67 / .68$ & $1 / 1$ & 0.4 & 6.9 & 6.5 & 6.3 & 5.3 & 5.1 & 5.1 \\
\hline 201 & $2.0 \mathrm{e} 11$ & $6 \mathrm{D}$ & 0.0005 & $.67 / .68$ & $1 / 1$ & 0.6 & 6.7 & 6.5 & 6.3 & 5.5 & 5.3 & 5.3 \\
\hline 202 & $2.0 \mathrm{e} 11$ & $6 \mathrm{D}$ & 0.0005 & $.67 / .68$ & $1 / 1$ & 0.8 & 6.5 & 6.7 & 6.1 & 5.9 & 5.3 & 5.3 \\
\hline 203 & $2.0 \mathrm{e} 11$ & $6 \mathrm{D}$ & 0.0005 & $.67 / .68$ & $1 / 1$ & 1.0 & 6.9 & 6.5 & 6.1 & 5.7 & 5.5 & 5.5 \\
\hline 204 & $2.0 \mathrm{e} 11$ & $6 \mathrm{D}$ & 0.0005 & $.67 / .68$ & $1 / 1$ & 1.2 & 7.1 & 6.7 & 6.1 & 5.7 & 5.5 & 5.5 \\
\hline
\end{tabular}




\begin{tabular}{|c|c|c|c|c|c|c|c|c|c|c|c|c|}
\hline 205 & $2.0 \mathrm{e} 11$ & $6 \mathrm{D}$ & 0.0005 & $.67 / .68$ & $1 / 1$ & 1.4 & 6.5 & 6.5 & 6.1 & 5.5 & 5.3 & 5.3 \\
\hline 206 & $2.0 \mathrm{e} 11$ & $6 \mathrm{D}$ & 0.0005 & $.67 / .68$ & $1 / 1$ & 1.6 & 6.5 & 6.7 & 6.1 & 5.5 & 5.1 & 5.1 \\
\hline 207 & $2.0 \mathrm{e} 11$ & $6 \mathrm{D}$ & 0.0005 & $.67 / .68$ & $1 / 1$ & 1.8 & 6.5 & 6.5 & 6.2 & 6.0 & 5.0 & 5.0 \\
\hline 208 & $2.0 e 11$ & $6 \mathrm{D}$ & 0.0005 & $.67 / .68$ & $1 / 1$ & 2.0 & 6.7 & 6.5 & 6.3 & 5.7 & 5.1 & 5.1 \\
\hline 209 & $2.5 e 11$ & $6 \mathrm{D}$ & 0.0005 & $.67 / .68$ & $1 / 1$ & 0.2 & 6.7 & 6.7 & 5.9 & 5.5 & 4.5 & 4.5 \\
\hline 210 & $2.5 e 11$ & $6 \mathrm{D}$ & 0.0005 & $.67 / .68$ & $1 / 1$ & 0.4 & 6.3 & 6.3 & 6.1 & 5.1 & 4.5 & 4.5 \\
\hline 211 & $2.5 e 11$ & $6 \mathrm{D}$ & 0.0005 & $.67 / .68$ & $1 / 1$ & 0.6 & 6.7 & 6.3 & 5.7 & 5.5 & 4.5 & 4.5 \\
\hline 212 & $2.5 \mathrm{e} 11$ & $6 \mathrm{D}$ & 0.0005 & $.67 / .68$ & $1 / 1$ & 0.8 & 6.5 & 6.1 & 5.9 & 5.1 & 4.5 & 4.5 \\
\hline 213 & $2.5 \mathrm{e} 11$ & $6 \mathrm{D}$ & 0.0005 & $.67 / .68$ & $1 / 1$ & 1.0 & 6.1 & 6.7 & 6.3 & 5.3 & 4.5 & 4.5 \\
\hline 214 & $2.5 e 11$ & $6 \mathrm{D}$ & 0.0005 & $.67 / .68$ & $1 / 1$ & 1.2 & 6.3 & 6.1 & 6.3 & 5.5 & 4.5 & 4.5 \\
\hline 215 & $2.5 e 11$ & $6 \mathrm{D}$ & 0.0005 & $.67 / .68$ & $1 / 1$ & 1.4 & 6.5 & 6.3 & 6.1 & 5.3 & 4.7 & 4.7 \\
\hline 216 & $2.5 \mathrm{e} 11$ & $6 \mathrm{D}$ & 0.0005 & $.67 / .68$ & $1 / 1$ & 1.6 & 6.5 & 6.3 & 5.9 & 5.3 & 4.5 & 4.5 \\
\hline 217 & $2.5 \mathrm{e} 11$ & $6 \mathrm{D}$ & 0.0005 & $.67 / .68$ & $1 / 1$ & 1.8 & 6.2 & 6.2 & 6.0 & 5.2 & 4.6 & 4.6 \\
\hline 218 & $2.5 e 11$ & $6 \mathrm{D}$ & 0.0005 & $.67 / .68$ & $1 / 1$ & 2.0 & 6.3 & 6.5 & 6.3 & 5.7 & 4.7 & 4.7 \\
\hline 219 & $3.0 \mathrm{e} 11$ & $6 \mathrm{D}$ & 0.0005 & $.67 / .68$ & $1 / 1$ & 0.2 & 6.3 & 6.1 & 5.7 & 4.7 & 4.3 & 4.3 \\
\hline 220 & $3.0 \mathrm{e} 11$ & $6 \mathrm{D}$ & 0.0005 & $.67 / .68$ & $1 / 1$ & 0.4 & 6.3 & 6.1 & 6.1 & 4.0 & 4.7 & 4.0 \\
\hline 221 & $3.0 \mathrm{e} 11$ & $6 \mathrm{D}$ & 0.0005 & $.67 / .68$ & $1 / 1$ & 0.6 & 6.3 & 5.7 & 5.9 & 4.5 & 4.0 & 4.0 \\
\hline 222 & $3.0 \mathrm{e} 11$ & $6 \mathrm{D}$ & 0.0005 & $.67 / .68$ & $1 / 1$ & 0.8 & 6.0 & 6.0 & 5.4 & 4.0 & 5.0 & 4.0 \\
\hline 223 & $3.0 \mathrm{e} 11$ & $6 \mathrm{D}$ & 0.0005 & $.67 / .68$ & $1 / 1$ & 1.0 & 5.7 & 6.5 & 5.3 & 4.5 & 4.7 & 4.5 \\
\hline 224 & $3.0 \mathrm{e} 11$ & $6 \mathrm{D}$ & 0.0005 & $.67 / .68$ & $1 / 1$ & 1.2 & 6.3 & 5.7 & 5.5 & 4.5 & 4.1 & 4.1 \\
\hline 225 & $3.0 \mathrm{e} 11$ & $6 \mathrm{D}$ & 0.0005 & $.67 / .68$ & $1 / 1$ & 1.4 & 5.5 & 5.7 & 5.7 & 5.1 & 4.0 & 4.0 \\
\hline 226 & $3.0 \mathrm{e} 11$ & $6 \mathrm{D}$ & 0.0005 & $.67 / .68$ & $1 / 1$ & 1.6 & 5.7 & 6.1 & 5.9 & 4.7 & 4.0 & 4.0 \\
\hline 227 & $3.0 \mathrm{e} 11$ & $6 \mathrm{D}$ & 0.0005 & $.67 / .68$ & $1 / 1$ & 1.8 & 5.9 & 6.3 & 5.3 & 5.5 & 3.8 & 3.8 \\
\hline 228 & $3.0 \mathrm{e} 11$ & $6 \mathrm{D}$ & 0.0005 & $.67 / .68$ & $1 / 1$ & 2.0 & 6.5 & 6.1 & 5.3 & 4.9 & 4.0 & 4.0 \\
\hline
\end{tabular}

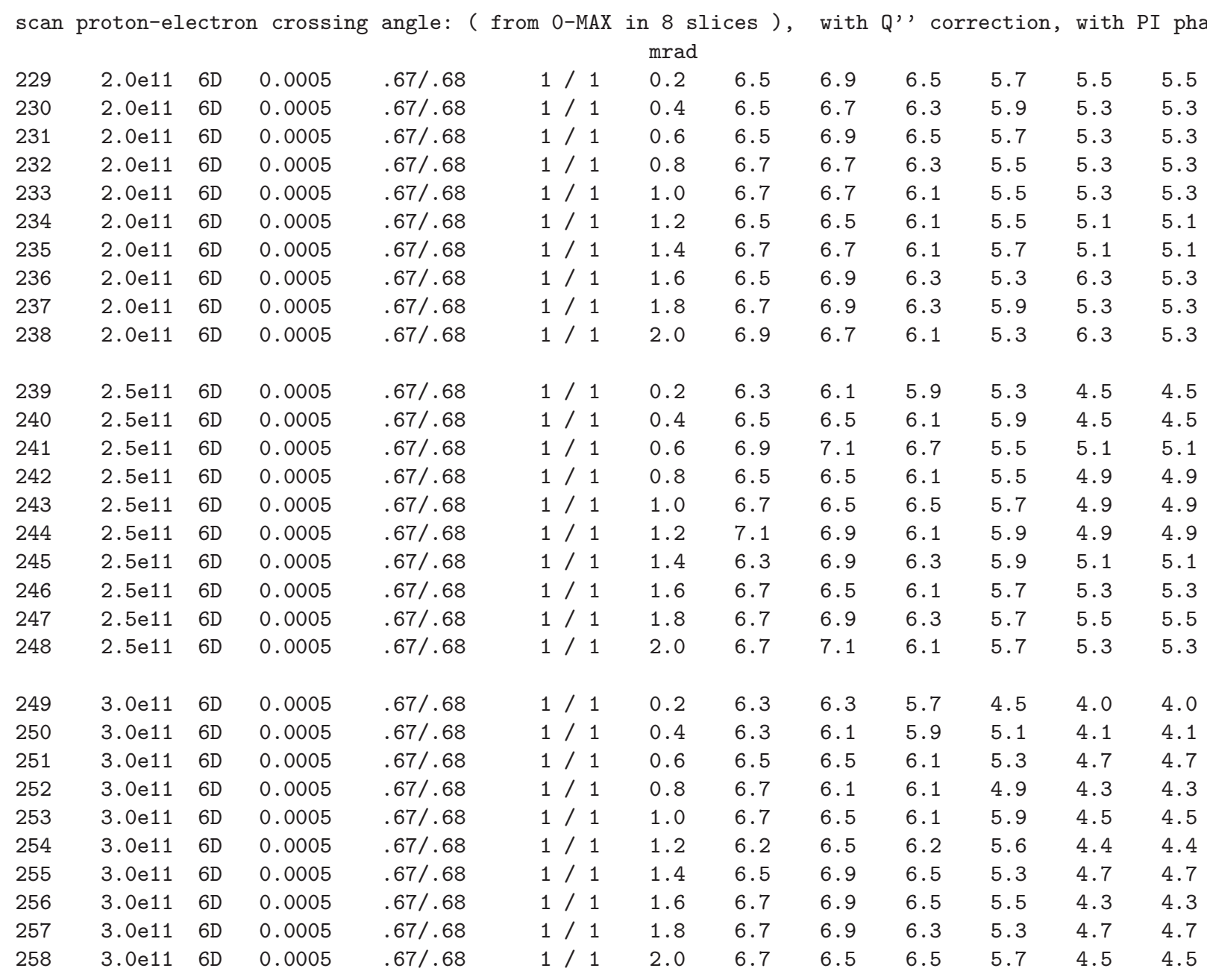


< Repeat 199-258, but with 1.2 larger electron beam, sigma_e = $1.2 *$ sigma_p $>>$

\begin{tabular}{|c|c|c|c|c|c|c|c|c|c|c|c|c|}
\hline & & & & & & offs & [sign & & & & & \\
\hline 259 & $2.0 \mathrm{e} 11$ & $6 \mathrm{D}$ & 0.0005 & $.67 / .68$ & $1 / 1$ & 0.2 & 6.9 & 7.1 & 6.5 & 5.5 & 5.1 & 5.1 \\
\hline 260 & $2.0 \mathrm{e} 11$ & $6 \mathrm{D}$ & 0.0005 & $.67 / .68$ & $1 / 1$ & 0.4 & 6.9 & 6.9 & 6.7 & 5.7 & 4.5 & 4.5 \\
\hline 261 & $2.0 \mathrm{e} 11$ & $6 \mathrm{D}$ & 0.0005 & $.67 / .68$ & $1 / 1$ & 0.6 & 7.3 & 7.1 & 6.7 & 6.3 & 6.3 & 6.3 \\
\hline 262 & $2.0 \mathrm{e} 11$ & $6 \mathrm{D}$ & 0.0005 & $.67 / .68$ & $1 / 1$ & 0.8 & 6.7 & 7.9 & 6.5 & 5.1 & 4.9 & 4.9 \\
\hline 263 & $2.0 \mathrm{e} 11$ & $6 \mathrm{D}$ & 0.0005 & $.67 / .68$ & $1 / 1$ & 1.0 & 7.3 & 6.9 & 6.7 & 6.1 & 5.3 & 5.3 \\
\hline 264 & $2.0 \mathrm{e} 11$ & $6 \mathrm{D}$ & 0.0005 & $.67 / .68$ & $1 / 1$ & 1.2 & 7.0 & 6.2 & 6.2 & 6.2 & & \\
\hline 265 & $2.0 \mathrm{e} 11$ & $6 \mathrm{D}$ & 0.0005 & $.67 / .68$ & $1 / 1$ & 1.4 & 7.5 & 7.3 & 7.1 & 5.9 & 4.5 & 4.5 \\
\hline 266 & $2.0 \mathrm{e} 11$ & $6 \mathrm{D}$ & 0.0005 & $.67 / .68$ & $1 / 1$ & 1.6 & 7.1 & 7.5 & 7.1 & 5.5 & 5.5 & 5.5 \\
\hline 267 & $2.0 \mathrm{e} 11$ & $6 \mathrm{D}$ & 0.0005 & $.67 / .68$ & $1 / 1$ & 1.8 & 6.9 & 6.1 & 7.3 & 6.3 & 5.3 & 5.3 \\
\hline 268 & $2.0 \mathrm{e} 11$ & $6 \mathrm{D}$ & 0.0005 & $.67 / .68$ & $1 / 1$ & 2.0 & 6.9 & 7.5 & 6.7 & 6.1 & 5.3 & 5.3 \\
\hline 269 & $2.5 e 11$ & $6 \mathrm{D}$ & 0.0005 & $.67 / .68$ & $1 / 1$ & 0.2 & 6.3 & 6.5 & 5.9 & 5.3 & 4.9 & 4.9 \\
\hline 270 & $2.5 e 11$ & $6 \mathrm{D}$ & 0.0005 & $.67 / .68$ & $1 / 1$ & 0.4 & 6.2 & 6.9 & 6.0 & 6.0 & 5.0 & 5.0 \\
\hline 271 & $2.5 e 11$ & $6 \mathrm{D}$ & 0.0005 & $.67 / .68$ & $1 / 1$ & 0.6 & 6.1 & 6.7 & 6.3 & 5.5 & 5.5 & 5.5 \\
\hline 272 & $2.5 e 11$ & $6 \mathrm{D}$ & 0.0005 & $.67 / .68$ & $1 / 1$ & 0.8 & 7.1 & 6.7 & 6.1 & 5.3 & 5.3 & 5.3 \\
\hline 273 & $2.5 \mathrm{e} 11$ & $6 \mathrm{D}$ & 0.0005 & $.67 / .68$ & $1 / 1$ & 1.0 & 6.5 & 6.5 & 5.9 & 5.9 & 4.9 & 4.9 \\
\hline 274 & $2.5 \mathrm{e} 11$ & $6 \mathrm{D}$ & 0.0005 & $.67 / .68$ & $1 / 1$ & 1.2 & 6.2 & 6.5 & 6.2 & 5.4 & 5.0 & 5.0 \\
\hline 275 & $2.5 \mathrm{e} 11$ & $6 \mathrm{D}$ & 0.0005 & $.67 / .68$ & $1 / 1$ & 1.4 & 6.2 & 6.5 & 6.2 & 5.6 & 5.4 & 5.4 \\
\hline 276 & $2.5 \mathrm{e} 11$ & $6 \mathrm{D}$ & 0.0005 & $.67 / .68$ & $1 / 1$ & 1.6 & 6.3 & 7.1 & 6.1 & 5.7 & 4.7 & 4.7 \\
\hline 277 & $2.5 \mathrm{e} 11$ & $6 \mathrm{D}$ & 0.0005 & $.67 / .68$ & $1 / 1$ & 1.8 & 6.5 & 6.7 & 6.1 & 6.3 & 5.3 & 5.3 \\
\hline 278 & $2.5 \mathrm{e} 11$ & $6 \mathrm{D}$ & 0.0005 & $.67 / .68$ & $1 / 1$ & 2.0 & 6.5 & 6.5 & 6.3 & 5.7 & 5.3 & 5.3 \\
\hline 279 & $3.0 \mathrm{e} 11$ & $6 \mathrm{D}$ & 0.0005 & $.67 / .68$ & $1 / 1$ & 0.2 & 6.0 & 5.6 & 5.4 & 4.8 & 4.4 & 4.4 \\
\hline 280 & 3. $0 \mathrm{e} 11$ & $6 \mathrm{D}$ & 0.0005 & $.67 / .68$ & $1 / 1$ & 0.4 & 5.6 & 5.6 & 5.0 & 4.6 & 4.4 & 4.4 \\
\hline 281 & $3.0 \mathrm{e} 11$ & $6 \mathrm{D}$ & 0.0005 & $.67 / .68$ & $1 / 1$ & 0.6 & 5.7 & 5.7 & 5.5 & 4.7 & 4.7 & 4.7 \\
\hline 282 & $3.0 \mathrm{e} 11$ & $6 \mathrm{D}$ & 0.0005 & $.67 / .68$ & $1 / 1$ & 0.8 & 5.8 & 6.2 & 5.0 & 5.4 & 4.4 & 4.4 \\
\hline 283 & $3.0 \mathrm{e} 11$ & $6 \mathrm{D}$ & 0.0005 & $.67 / .68$ & $1 / 1$ & 1.0 & 5.7 & 5.5 & 6.3 & 4.7 & 4.7 & 4.7 \\
\hline 284 & $3.0 \mathrm{e} 11$ & $6 \mathrm{D}$ & 0.0005 & $.67 / .68$ & $1 / 1$ & 1.2 & 5.9 & 5.5 & 5.1 & 4.7 & 4.5 & 4.5 \\
\hline 285 & $3.0 \mathrm{e} 11$ & $6 \mathrm{D}$ & 0.0005 & $.67 / .68$ & $1 / 1$ & 1.4 & 6.7 & 5.9 & 6.3 & 4.1 & 4.1 & 4.1 \\
\hline 286 & $3.0 \mathrm{e} 11$ & $6 \mathrm{D}$ & 0.0005 & $.67 / .68$ & $1 / 1$ & 1.6 & 6.0 & 6.2 & 5.3 & 5.6 & 4.4 & 4.4 \\
\hline 287 & $3.0 \mathrm{e} 11$ & $6 \mathrm{D}$ & 0.0005 & $.67 / .68$ & $1 / 1$ & 1.8 & 5.2 & 6.0 & 6.0 & 4.6 & 4.4 & 4.4 \\
\hline 288 & $3.0 \mathrm{e} 11$ & $6 \mathrm{D}$ & 0.0005 & $.67 / .68$ & $1 / 1$ & 2.0 & 6.7 & 6.3 & 5.5 & 4.5 & 5.1 & 4.5 \\
\hline
\end{tabular}

scan proton-electron crossing angle: ( from 0-MAX in 8 slices), with Q'' correction, with PI phasers

\begin{tabular}{|c|c|c|c|c|c|c|c|c|c|c|c|c|}
\hline & & & & & & mrad & & & & & & \\
\hline 289 & $2.0 \mathrm{e} 11$ & $6 \mathrm{D}$ & 0.0005 & $.67 / .68$ & $1 / 1$ & 0.2 & 7.1 & 7.3 & 6.7 & 5.9 & 5.1 & 5.1 \\
\hline 290 & $2.0 \mathrm{e} 11$ & $6 \mathrm{D}$ & 0.0005 & $.67 / .68$ & $1 / 1$ & 0.4 & 6.9 & 7.9 & 6.7 & 5.3 & 5.5 & 5.3 \\
\hline 291 & $2.0 \mathrm{e} 11$ & $6 \mathrm{D}$ & 0.0005 & $.67 / .68$ & $1 / 1$ & 0.6 & 7.1 & 7.1 & 6.7 & 6.3 & 5.5 & 5.5 \\
\hline 292 & $2.0 \mathrm{e} 11$ & $6 \mathrm{D}$ & 0.0005 & $.67 / .68$ & $1 / 1$ & 0.8 & 6.9 & 7.3 & 6.2 & 6.2 & 5.4 & 5.4 \\
\hline 293 & $2.0 \mathrm{e} 11$ & $6 \mathrm{D}$ & 0.0005 & $.67 / .68$ & $1 / 1$ & 1.0 & 7.3 & 7.3 & 6.9 & 6.3 & 5.1 & 5.1 \\
\hline 294 & $2.0 \mathrm{e} 11$ & $6 \mathrm{D}$ & 0.0005 & $.67 / .68$ & $1 / 1$ & 1.2 & 7.1 & 7.5 & 7.1 & 6.1 & 4.9 & 4.9 \\
\hline 295 & $2.0 \mathrm{e} 11$ & $6 \mathrm{D}$ & 0.0005 & $.67 / .68$ & $1 / 1$ & 1.4 & 7.1 & 7.5 & 7.3 & 5.7 & 5.3 & 5.3 \\
\hline 296 & $2.0 \mathrm{e} 11$ & $6 \mathrm{D}$ & 0.0005 & $.67 / .68$ & $1 / 1$ & 1.6 & 7.5 & 7.3 & 7.1 & 6.3 & 4.9 & 4.9 \\
\hline 297 & $2.0 \mathrm{e} 11$ & $6 \mathrm{D}$ & 0.0005 & $.67 / .68$ & $1 / 1$ & 1.8 & 6.9 & 7.3 & 6.5 & 6.1 & 5.5 & 5.5 \\
\hline 298 & $2.0 \mathrm{e} 11$ & $6 \mathrm{D}$ & 0.0005 & $.67 / .68$ & $1 / 1$ & 2.0 & 7.3 & 6.9 & 7.1 & 5.7 & 5.9 & 5.7 \\
\hline 299 & $2.5 e 11$ & $6 \mathrm{D}$ & 0.0005 & $.67 / .68$ & $1 / 1$ & 0.2 & 6.5 & 7.1 & 5.9 & 5.5 & 5.1 & 5.1 \\
\hline 300 & $2.5 \mathrm{e} 11$ & $6 \mathrm{D}$ & 0.0005 & $.67 / .68$ & $1 / 1$ & 0.4 & 6.7 & 6.7 & 5.9 & 5.9 & 5.1 & 5.1 \\
\hline 301 & $2.5 e 11$ & $6 \mathrm{D}$ & 0.0005 & $.67 / .68$ & $1 / 1$ & 0.6 & 6.9 & 6.5 & 6.3 & 5.9 & 5.5 & 5.5 \\
\hline 302 & $2.5 e 11$ & $6 \mathrm{D}$ & 0.0005 & $.67 / .68$ & $1 / 1$ & 0.8 & 6.9 & 7.3 & 7.1 & 5.3 & 4.9 & 4.9 \\
\hline 303 & $2.5 e 11$ & $6 \mathrm{D}$ & 0.0005 & $.67 / .68$ & $1 / 1$ & 1.0 & 6.7 & 6.5 & 7.1 & 5.3 & 5.3 & 5.3 \\
\hline 304 & $2.5 e 11$ & $6 \mathrm{D}$ & 0.0005 & $.67 / .68$ & $1 / 1$ & 1.2 & 7.1 & 6.9 & 6.7 & 6.3 & 5.1 & 5.1 \\
\hline 305 & $2.5 \mathrm{e} 11$ & $6 \mathrm{D}$ & 0.0005 & $.67 / .68$ & $1 / 1$ & 1.4 & 6.9 & 6.7 & 6.5 & 6.3 & 4.9 & 4.9 \\
\hline 306 & $2.5 \mathrm{e} 11$ & $6 \mathrm{D}$ & 0.0005 & $.67 / .68$ & $1 / 1$ & 1.6 & 6.5 & 6.9 & 6.7 & 5.9 & 5.5 & 5.5 \\
\hline 307 & $2.5 \mathrm{e} 11$ & $6 \mathrm{D}$ & 0.0005 & $.67 / .68$ & $1 / 1$ & 1.8 & 6.7 & 7.9 & 7.1 & 5.9 & 5.1 & 5.1 \\
\hline
\end{tabular}




\begin{tabular}{|c|c|c|c|c|c|c|c|c|c|c|c|c|}
\hline 308 & $2.5 e 11$ & $6 \mathrm{D}$ & 0.0005 & $.67 / .68$ & $1 / 1$ & 2.0 & 7.1 & 6.9 & 6.7 & 5.7 & 5.7 & 5.7 \\
\hline 309 & $3.0 \mathrm{e} 11$ & $6 \mathrm{D}$ & 0.0005 & $.67 / .68$ & $1 / 1$ & 0.2 & 6.3 & 5.3 & 5.9 & 5.1 & 4.9 & 4.9 \\
\hline 310 & $3.0 \mathrm{e} 11$ & $6 \mathrm{D}$ & 0.0005 & $.67 / .68$ & $1 / 1$ & 0.4 & 6.1 & 6.3 & 5.3 & 5.1 & 4.7 & 4.7 \\
\hline 311 & $3.0 \mathrm{e} 11$ & $6 \mathrm{D}$ & 0.0005 & $.67 / .68$ & $1 / 1$ & 0.6 & 6.3 & 5.3 & 4.5 & 4.9 & 4.3 & 4.3 \\
\hline 312 & $3.0 \mathrm{e} 11$ & $6 \mathrm{D}$ & 0.0005 & $.67 / .68$ & $1 / 1$ & 0.8 & 6.3 & 6.3 & 5.7 & 5.1 & 5.1 & 5.1 \\
\hline 313 & $3.0 \mathrm{e} 11$ & $6 \mathrm{D}$ & 0.0005 & $.67 / .68$ & $1 / 1$ & 1.0 & 6.9 & 5.9 & 6.3 & 4.5 & 4.3 & 4.3 \\
\hline 314 & $3.0 \mathrm{e} 11$ & $6 \mathrm{D}$ & 0.0005 & $.67 / .68$ & $1 / 1$ & 1.2 & 6.7 & 6.1 & 6.3 & 4.7 & 5.1 & 4.7 \\
\hline 315 & $3.0 e 11$ & $6 \mathrm{D}$ & 0.0005 & $.67 / .68$ & $1 / 1$ & 1.4 & 6.5 & 6.3 & 5.5 & 4.9 & 5.1 & 4.9 \\
\hline 316 & $3.0 \mathrm{e} 11$ & $6 \mathrm{D}$ & 0.0005 & $.67 / .68$ & $1 / 1$ & 1.6 & 6.7 & 6.7 & 5.3 & 4.9 & 5.5 & 4.9 \\
\hline 317 & $3.0 \mathrm{e} 11$ & $6 \mathrm{D}$ & 0.0005 & $.67 / .68$ & $1 / 1$ & 1.8 & 6.9 & 5.9 & 7.1 & 5.5 & 4.5 & 4.5 \\
\hline 318 & $3.0 \mathrm{e} 11$ & $6 \mathrm{D}$ & 0.0005 & $.67 / .68$ & $1 / 1$ & 2.0 & 6.7 & 5.7 & 5.9 & 4.7 & 5.1 & 4.7 \\
\hline
\end{tabular}

Scan proton beam working points, with Q', correction, with PI phasers

baseline copied from workshop126

$\begin{array}{llllllllllll}474 & 2.0 \mathrm{e} 11 & 6 \mathrm{D} & 0.0005 & 0.67 / 0.675 & 1 / 1 & 6.3 & 6.1 & 6.7 & 5.9 & 5.3 & 5.3 \\ 475 & 2.0 \mathrm{e} 11 & 6 \mathrm{D} & 0.0005 & 0.675 / 0.680 & 1 / 1 & 7.9 & 6.5 & 6.7 & 5.7 & 5.7 & 5.7 \\ 476 & 2.0 \mathrm{e} 11 & 6 \mathrm{D} & 0.0005 & 0.680 / 0.685 & 1 / 1 & 5.3 & 5.5 & 5.7 & 4.5 & 4.3 & 4.3 \\ 477 & 2.0 \mathrm{e} 11 & 6 \mathrm{D} & 0.0005 & 0.685 / 0.68 & 1 / 1 & 5.9 & 4.3 & 5.7 & 5.9 & 5.7 & 4.3 \\ 478 & 2.0 \mathrm{e} 11 & 6 \mathrm{D} & 0.0005 & 0.68 / 0.675 & 1 / 1 & 6.5 & 5.9 & 6.5 & 6.9 & 6.3 & 5.9 \\ 479 & 2.0 \mathrm{e} 11 & 6 \mathrm{D} & 0.0005 & 0.675 / 0.67 & 1 / 1 & 5.3 & 5.7 & 6.3 & 6.3 & 6.1 & 5.3\end{array}$

baseline copied from workshop135

$\begin{array}{llllllllllll}480 & 2.5 \mathrm{e} 11 & 6 \mathrm{D} & 0.0005 & 0.67 / 0.675 & 1 / 1 & 6.1 & 6.7 & 6.1 & 5.9 & 4.9 & 4.9 \\ 481 & 2.5 \mathrm{e} 11 & 6 \mathrm{D} & 0.0005 & 0.675 / 0.680 & 1 / 1 & 5.7 & 5.7 & 5.5 & 5.3 & 4.7 & 4.7 \\ 482 & 2.5 \mathrm{e} 11 & 6 \mathrm{D} & 0.0005 & 0.680 / 0.685 & 1 / 1 & 5.3 & 5.7 & 5.1 & 4.7 & 5.1 & 4.7 \\ 483 & 2.5 \mathrm{e} 11 & 6 \mathrm{D} & 0.0005 & 0.685 / 0.68 & 1 / 1 & 6.3 & 4.3 & 5.1 & 5.1 & 4.5 & 4.3 \\ 484 & 2.5 \mathrm{e} 11 & 6 \mathrm{D} & 0.0005 & 0.68 / 0.675 & 1 / 1 & 5.9 & 5.5 & 6.1 & 5.9 & 7.1 & 5.5 \\ 485 & 2.5 \mathrm{e} 11 & 6 \mathrm{D} & 0.0005 & 0.675 / 0.67 & 1 / 1 & 5.9 & 5.7 & 6.5 & 6.7 & 6.5 & 5.7\end{array}$

baseline copied from workshop146

$\begin{array}{llllllllllll}486 & 3.0 \mathrm{e} 11 & 6 \mathrm{D} & 0.0005 & 0.67 / 0.675 & 1 / 1 & 6.5 & 6.1 & 6.1 & 5.5 & 5.5 & 5.5 \\ 487 & 3.0 \mathrm{e} 11 & 6 \mathrm{D} & 0.0005 & 0.675 / 0.680 & 1 / 1 & 6.1 & 4.7 & 5.9 & 4.0 & 3.8 & 3.8 \\ 488 & 3.0 \mathrm{e} 11 & 6 \mathrm{D} & 0.0005 & 0.680 / 0.685 & 1 / 1 & 4.1 & 3.8 & 3.8 & 4.1 & 4.1 & 3.8 \\ 489 & 3.0 \mathrm{e} 11 & 6 \mathrm{D} & 0.0005 & 0.685 / 0.68 & 1 / 1 & 5.9 & 4.9 & 4.0 & 4.7 & 3.8 & 3.8 \\ 490 & 3.0 \mathrm{e} 11 & 6 \mathrm{D} & 0.0005 & 0.68 / 0.675 & 1 / 1 & 6.3 & 5.1 & 5.7 & 5.7 & 5.3 & 5.1 \\ 491 & 3.0 \mathrm{e} 11 & 6 \mathrm{D} & 0.0005 & 0.675 / 0.67 & 1 / 1 & 5.5 & 5.7 & 6.3 & 6.9 & 6.5 & 5.5\end{array}$

Summary of DA calculation with HBBC, PI phasers, Q' correction.

scan proton bunch intensity, baseline copied from workshop135

( workshop259-302 DA_binary1.cpp destoryed unfortunately and DA_binary_search1 reproduced)

< BB at IP6 and IP8, no Q', correct. >

$\begin{array}{lllllllllllll}492 & 1.2 \mathrm{e} 11 & 6 \mathrm{D} & 0.0003 & 0.67 / 0.68 & 1 / 1 & 7.7 & 7.5 & 6.9 & 6.1 & 6.5 & 6.1 \\ 493 & 1.4 \mathrm{e} 11 & 6 \mathrm{D} & 0.0003 & 0.67 / 0.68 & 1 / 1 & 7.9 & 7.5 & 7.5 & 6.1 & 5.9 & 5.9 \\ 494 & 1.6 \mathrm{e} 11 & 6 \mathrm{D} & 0.0003 & 0.67 / 0.68 & 1 / 1 & 7.9 & 7.7 & 7.9 & 6.7 & 6.1 & 6.1 \\ 495 & 1.8 \mathrm{e} 11 & 6 \mathrm{D} & 0.0003 & 0.67 / 0.68 & 1 / 1 & 7.7 & 7.7 & 7.1 & 6.7 & 5.9 & 5.9 \\ 496 & 2.0 \mathrm{e} 11 & 6 \mathrm{D} & 0.0003 & 0.67 / 0.68 & 1 / 1 & 7.1 & 7.9 & 7.3 & 6.5 & 5.7 & 5.7 \\ 497 & 2.2 \mathrm{e} 11 & 6 \mathrm{D} & 0.0003 & 0.67 / 0.68 & 1 / 1 & 8.4 & 6.9 & 6.5 & 6.1 & 6.9 & 6.1 \\ 498 & 2.4 \mathrm{e} 11 & 6 \mathrm{D} & 0.0003 & 0.67 / 0.68 & 1 / 1 & 8.1 & 6.1 & 6.7 & 6.3 & 5.7 & 5.7 \\ 499 & 2.6 \mathrm{e} 11 & 6 \mathrm{D} & 0.0003 & 0.67 / 0.68 & 1 / 1 & 7.3 & 6.7 & 5.9 & 4.7 & 6.3 & 4.7 \\ 500 & 2.8 \mathrm{e} 11 & 6 \mathrm{D} & 0.0003 & 0.67 / 0.68 & 1 / 1 & 6.7 & 6.5 & 5.7 & 5.3 & 5.7 & 5.3 \\ 501 & 3.0 \mathrm{e} 11 & 6 \mathrm{D} & 0.0003 & 0.67 / 0.68 & 1 / 1 & 5.7 & 4.7 & 4.5 & 4.3 & 6.7 & 4.3\end{array}$




$\begin{array}{lllllllllllll}502 & 1.2 \mathrm{e} 11 & 6 \mathrm{D} & 0.0005 & 0.67 / 0.68 & 1 / 1 & 7.7 & 7.9 & 6.7 & 5.7 & 5.7 & 5.7 \\ 503 & 1.4 \mathrm{e} 11 & 6 \mathrm{D} & 0.0005 & 0.67 / 0.68 & 1 / 1 & 7.5 & 7.3 & 7.1 & 6.1 & 5.3 & 5.3 \\ 504 & 1.6 \mathrm{e} 11 & 6 \mathrm{D} & 0.0005 & 0.67 / 0.68 & 1 / 1 & 7.7 & 7.5 & 6.9 & 6.1 & 5.7 & 5.7 \\ 505 & 1.8 \mathrm{e} 11 & 6 \mathrm{D} & 0.0005 & 0.67 / 0.68 & 1 / 1 & 6.9 & 7.5 & 6.9 & 5.9 & 5.9 & 5.9 \\ 506 & 2.0 \mathrm{e} 11 & 6 \mathrm{D} & 0.0005 & 0.67 / 0.68 & 1 / 1 & 6.9 & 6.7 & 6.3 & 5.5 & 4.9 & 4.9 \\ 507 & 2.2 \mathrm{e} 11 & 6 \mathrm{D} & 0.0005 & 0.67 / 0.68 & 1 / 1 & 5.5 & 5.5 & 6.3 & 4.3 & 4.3 & 4.3 \\ 508 & 2.4 \mathrm{e} 11 & 6 \mathrm{D} & 0.0005 & 0.67 / 0.68 & 1 / 1 & 7.1 & 4.9 & 5.1 & 3.8 & 5.1 & 3.8 \\ 509 & 2.6 \mathrm{e} 11 & 6 \mathrm{D} & 0.0005 & 0.67 / 0.68 & 1 / 1 & 5.9 & 5.3 & 4.0 & 4.0 & 3.8 & 3.8 \\ 510 & 2.8 \mathrm{e} 11 & 6 \mathrm{D} & 0.0005 & 0.67 / 0.68 & 1 / 1 & 6.1 & 5.1 & 3.6 & 3.0 & 4.7 & 3.0 \\ 511 & 3.0 \mathrm{e} 11 & 6 \mathrm{D} & 0.0005 & 0.67 / 0.68 & 1 / 1 & 4.7 & 4.0 & 3.2 & 2.8 & 4.1 & 2.8\end{array}$

< BB at IP6 and IP8, with Q', correct. >

$\begin{array}{lllllllllllll}580 & 1.2 \mathrm{e} 11 & 6 \mathrm{D} & 0.0003 & 0.67 / 0.68 & 1 / 1 & 7.7 & 7.3 & 6.9 & 6.7 & 6.5 & 6.5 \\ 581 & 1.4 \mathrm{e} 11 & 6 \mathrm{D} & 0.0003 & 0.67 / 0.68 & 1 / 1 & 7.7 & 7.7 & 7.7 & 6.3 & 6.7 & 6.3 \\ 582 & 1.6 \mathrm{e} 11 & 6 \mathrm{D} & 0.0003 & 0.67 / 0.68 & 1 / 1 & 8.4 & 8.1 & 7.7 & 6.7 & 7.3 & 6.7 \\ 583 & 1.8 \mathrm{e} 11 & 6 \mathrm{D} & 0.0003 & 0.67 / 0.68 & 1 / 1 & 7.7 & 7.5 & 7.5 & 6.7 & 6.7 & 6.7 \\ 584 & 2.0 \mathrm{e} 11 & 6 \mathrm{D} & 0.0003 & 0.67 / 0.68 & 1 / 1 & 7.9 & 8.1 & 7.5 & 6.1 & 5.9 & 5.9 \\ 585 & 2.2 \mathrm{e} 11 & 6 \mathrm{D} & 0.0003 & 0.67 / 0.68 & 1 / 1 & 8.4 & 8.1 & 6.5 & 7.1 & 6.9 & 6.5 \\ 586 & 2.4 \mathrm{e} 11 & 6 \mathrm{D} & 0.0003 & 0.67 / 0.68 & 1 / 1 & 8.1 & 8.1 & 6.1 & 6.5 & 5.9 & 5.9 \\ 587 & 2.6 \mathrm{e} 11 & 6 \mathrm{D} & 0.0003 & 0.67 / 0.68 & 1 / 1 & 6.5 & 7.5 & 5.3 & 4.9 & 6.7 & 4.9 \\ 588 & 2.8 \mathrm{e} 11 & 6 \mathrm{D} & 0.0003 & 0.67 / 0.68 & 1 / 1 & 6.7 & 6.7 & 5.5 & 5.9 & 6.1 & 5.5 \\ 589 & 3.0 \mathrm{e} 11 & 6 \mathrm{D} & 0.0003 & 0.67 / 0.68 & 1 / 1 & 5.3 & 4.7 & 4.5 & 4.3 & 6.9 & 4.3 \\ & & & & & & & & & & & & \\ 590 & 1.2 \mathrm{e} 11 & 6 \mathrm{D} & 0.0005 & 0.67 / 0.68 & 1 / 1 & 7.3 & 7.3 & 6.7 & 6.1 & 6.3 & 6.1 \\ 591 & 1.4 \mathrm{e} 11 & 6 \mathrm{D} & 0.0005 & 0.67 / 0.68 & 1 / 1 & 7.3 & 7.9 & 6.9 & 5.9 & 5.7 & 5.7 \\ 592 & 1.6 \mathrm{e} 11 & 6 \mathrm{D} & 0.0005 & 0.67 / 0.68 & 1 / 1 & 7.9 & 7.9 & 6.9 & 7.1 & 5.7 & 5.7 \\ 593 & 1.8 \mathrm{e} 11 & 6 \mathrm{D} & 0.0005 & 0.67 / 0.68 & 1 / 1 & 7.9 & 7.5 & 6.9 & 6.3 & 5.7 & 5.7 \\ 594 & 2.0 \mathrm{e} 11 & 6 \mathrm{D} & 0.0005 & 0.67 / 0.68 & 1 / 1 & 7.1 & 6.9 & 5.9 & 6.3 & 5.7 & 5.7 \\ 595 & 2.2 \mathrm{e} 11 & 6 \mathrm{D} & 0.0005 & 0.67 / 0.68 & 1 / 1 & 6.1 & 6.3 & 5.9 & 4.7 & 5.9 & 4.7 \\ 596 & 2.4 \mathrm{e} 11 & 6 \mathrm{D} & 0.0005 & 0.67 / 0.68 & 1 / 1 & 5.7 & 5.3 & 4.7 & 4.5 & 4.1 & 4.1 \\ 597 & 2.6 \mathrm{e} 11 & 6 \mathrm{D} & 0.0005 & 0.67 / 0.68 & 1 / 1 & 6.1 & 6.5 & 4.1 & 3.8 & 4.3 & 3.8 \\ 598 & 2.8 \mathrm{e} 11 & 6 \mathrm{D} & 0.0005 & 0.67 / 0.68 & 1 / 1 & 6.3 & 5.9 & 3.6 & 5.1 & 6.3 & 3.6 \\ 599 & 3.0 \mathrm{e} 11 & 6 \mathrm{D} & 0.0005 & 0.67 / 0.68 & 1 / 1 & 4.7 & 3.6 & 3.4 & 4.0 & 4.3 & 3.4\end{array}$

< With HBBC, no Q', correct. >

\begin{tabular}{|c|c|c|c|c|c|c|c|c|c|c|c|c|}
\hline 512 & 1. $2 \mathrm{e} 11$ & $6 \mathrm{D}$ & 0.0003 & 0.67 & / 0.68 & $1 / 1$ & 6.7 & 5.7 & 4.9 & 5.3 & 4.7 & 4.7 \\
\hline 513 & $1.4 \mathrm{e} 11$ & $6 \mathrm{D}$ & 0.0003 & 0.67 & $/ 0.68$ & $1 / 1$ & 6.5 & 5.7 & 5.3 & 4.5 & 4.9 & 4.5 \\
\hline 514 & $1.6 \mathrm{e} 11$ & $6 \mathrm{D}$ & 0.0003 & 0.67 & $/ 0.68$ & $1 / 1$ & 6.7 & 6.3 & 5.3 & 4.7 & 4.9 & 4.7 \\
\hline 515 & $1.8 \mathrm{e} 11$ & $6 \mathrm{D}$ & 0.0003 & 0.67 & / 0.68 & $1 / 1$ & 6.9 & 6.3 & 5.9 & 4.7 & 4.9 & 4.7 \\
\hline 516 & $2.0 \mathrm{e} 11$ & $6 \mathrm{D}$ & 0.0003 & 0.67 & / 0.68 & $1 / 1$ & 6.7 & 6.7 & 5.7 & 5.1 & 4.7 & 4.7 \\
\hline 517 & $2.2 \mathrm{e} 11$ & $6 \mathrm{D}$ & 0.0003 & 0.67 & $/ 0.68$ & $1 / 1$ & 6.5 & 6.9 & 5.3 & 5.3 & 4.9 & 4.9 \\
\hline 518 & $2.4 \mathrm{e} 11$ & $6 \mathrm{D}$ & 0.0003 & 0.67 & $/ 0.68$ & $1 / 1$ & 6.7 & 6.9 & 5.7 & 5.5 & 5.3 & 5.3 \\
\hline 519 & $2.6 \mathrm{e} 11$ & $6 \mathrm{D}$ & 0.0003 & 0.67 & / 0.68 & $1 / 1$ & 6.7 & 5.9 & 5.9 & 5.5 & 4.9 & 4.9 \\
\hline 520 & $2.8 \mathrm{e} 11$ & $6 \mathrm{D}$ & 0.0003 & 0.67 & / 0.68 & $1 / 1$ & 5.9 & 5.9 & 5.9 & 4.9 & 4.9 & 4.9 \\
\hline 521 & $3.0 \mathrm{e} 11$ & $6 \mathrm{D}$ & 0.0003 & 0.67 & / 0.68 & $1 / 1$ & 6.1 & 5.7 & 5.9 & 4.5 & 4.3 & 4.3 \\
\hline 522 & 1. $2 \mathrm{e} 11$ & $6 \mathrm{D}$ & 0.0005 & 0.67 & / 0.68 & $1 / 1$ & 6.3 & 5.5 & 4.7 & 4.5 & 4.9 & 4.5 \\
\hline 523 & $1.4 \mathrm{e} 11$ & $6 \mathrm{D}$ & 0.0005 & 0.67 & / 0.68 & $1 / 1$ & 6.1 & 5.7 & 4.3 & 4.3 & 4.3 & 4.3 \\
\hline 524 & $1.6 \mathrm{e} 11$ & $6 \mathrm{D}$ & 0.0005 & 0.67 & / 0.68 & $1 / 1$ & 6.5 & 5.5 & 4.9 & 4.5 & 4.7 & 4.5 \\
\hline 525 & $1.8 \mathrm{e} 11$ & $6 \mathrm{D}$ & 0.0005 & 0.67 & $/ 0.68$ & $1 / 1$ & 6.1 & 5.9 & 5.9 & 4.9 & 4.9 & 4.9 \\
\hline 526 & $2.0 \mathrm{e} 11$ & $6 \mathrm{D}$ & 0.0005 & 0.67 & / 0.68 & $1 / 1$ & 6.3 & 6.1 & 5.7 & 4.7 & 4.7 & 4.7 \\
\hline 527 & $2.2 \mathrm{e} 11$ & $6 \mathrm{D}$ & 0.0005 & 0.67 & / 0.68 & $1 / 1$ & 6.3 & 5.9 & 5.9 & 4.9 & 4.7 & 4.7 \\
\hline 528 & $2.4 \mathrm{e} 11$ & $6 \mathrm{D}$ & 0.0005 & 0.67 & / 0.68 & $1 / 1$ & 6.5 & 6.3 & 5.5 & 5.1 & 4.7 & 4.7 \\
\hline 529 & $2.6 e 11$ & $6 \mathrm{D}$ & 0.0005 & 0.67 & / 0.68 & $1 / 1$ & 6.5 & 6.3 & 4.9 & 5.5 & 4.5 & 4.5 \\
\hline 530 & $2.8 e 11$ & $6 \mathrm{D}$ & 0.0005 & 0.67 & / 0.68 & $1 / 1$ & 6.1 & 5.7 & 4.9 & 4.5 & 4.1 & 4.1 \\
\hline 531 & $3.0 \mathrm{e} 11$ & $6 \mathrm{D}$ & 0.0005 & 0.67 & $/ 0.68$ & $1 / 1$ & 5.7 & 6.3 & 4.9 & 4.9 & 4.3 & 4.3 \\
\hline
\end{tabular}

< With BBC, with PI phasers, no Q' correct. > 


\begin{tabular}{|c|c|c|c|c|c|c|c|c|c|c|c|c|}
\hline 532 & 1. $2 \mathrm{e} 11$ & $6 \mathrm{D}$ & 0.0003 & 0.67 & / 0.68 & $1 / 1$ & 6.7 & 6.3 & 5.7 & 5.7 & 5.1 & 5.1 \\
\hline 533 & $1.4 \mathrm{e} 11$ & $6 \mathrm{D}$ & 0.0003 & 0.67 & $/ 0.68$ & $1 / 1$ & 6.5 & 6.7 & 5.9 & 5.9 & 5.3 & 5.3 \\
\hline 534 & $1.6 \mathrm{e} 11$ & $6 \mathrm{D}$ & 0.0003 & 0.67 & $/ 0.68$ & $1 / 1$ & 6.7 & 6.5 & 6.1 & 6.3 & 5.3 & 5.3 \\
\hline 535 & $1.8 \mathrm{e} 11$ & $6 \mathrm{D}$ & 0.0003 & 0.67 & $/ 0.68$ & $1 / 1$ & 6.9 & 6.9 & 6.3 & 5.7 & 5.1 & 5.1 \\
\hline 536 & $2.0 \mathrm{e} 11$ & $6 \mathrm{D}$ & 0.0003 & 0.67 & / 0.68 & $1 / 1$ & 6.9 & 6.7 & 6.5 & 5.7 & 5.7 & 5.7 \\
\hline 537 & $2.2 e 11$ & $6 \mathrm{D}$ & 0.0003 & 0.67 & $/ 0.68$ & $1 / 1$ & 6.7 & 6.9 & 6.3 & 5.7 & 5.3 & 5.3 \\
\hline 538 & $2.4 \mathrm{e} 11$ & $6 \mathrm{D}$ & 0.0003 & 0.67 & $/ 0.68$ & $1 / 1$ & 6.7 & 6.7 & 6.1 & 5.5 & 5.3 & 5.3 \\
\hline 539 & $2.6 \mathrm{e} 11$ & $6 \mathrm{D}$ & 0.0003 & 0.67 & / 0.68 & $1 / 1$ & 6.3 & 6.3 & 5.7 & 4.9 & 5.1 & 4.9 \\
\hline 540 & $2.8 \mathrm{e} 11$ & $6 \mathrm{D}$ & 0.0003 & 0.67 & $/ 0.68$ & $1 / 1$ & 6.7 & 6.5 & 6.5 & 5.9 & 4.3 & 4.3 \\
\hline 541 & $3.0 \mathrm{e} 11$ & $6 \mathrm{D}$ & 0.0003 & 0.67 & $/ 0.68$ & $1 / 1$ & 6.5 & 5.9 & 5.7 & 4.3 & 4.1 & 4.1 \\
\hline 542 & $1.2 \mathrm{e} 11$ & $6 \mathrm{D}$ & 0.0005 & 0.67 & $/ 0.68$ & $1 / 1$ & 6.5 & 6.3 & 5.3 & 5.7 & 4.9 & 4.9 \\
\hline 543 & $1.4 \mathrm{e} 11$ & $6 \mathrm{D}$ & 0.0005 & 0.67 & / 0.68 & $1 / 1$ & 6.5 & 6.7 & 5.7 & 5.7 & 5.3 & 5.3 \\
\hline 544 & $1.6 \mathrm{e} 11$ & $6 \mathrm{D}$ & 0.0005 & 0.67 & $/ 0.68$ & $1 / 1$ & 6.9 & 6.5 & 5.9 & 5.1 & 4.9 & 4.9 \\
\hline 545 & $1.8 \mathrm{e} 11$ & $6 \mathrm{D}$ & 0.0005 & 0.67 & $/ 0.68$ & $1 / 1$ & 6.7 & 6.7 & 6.1 & 5.5 & 5.5 & 5.5 \\
\hline 546 & $2.0 \mathrm{e} 11$ & $6 \mathrm{D}$ & 0.0005 & 0.67 & $/ 0.68$ & $1 / 1$ & 6.9 & 6.9 & 6.3 & 5.3 & 5.5 & 5.3 \\
\hline 547 & $2.2 \mathrm{e} 11$ & $6 \mathrm{D}$ & 0.0005 & 0.67 & $/ 0.68$ & $1 / 1$ & 7.1 & 6.7 & 6.3 & 5.5 & 5.3 & 5.3 \\
\hline 548 & $2.4 \mathrm{e} 11$ & $6 \mathrm{D}$ & 0.0005 & 0.67 & $/ 0.68$ & $1 / 1$ & 6.5 & 6.7 & 6.1 & 5.3 & 4.7 & 4.7 \\
\hline 549 & $2.6 \mathrm{e} 11$ & $6 \mathrm{D}$ & 0.0005 & 0.67 & $/ 0.68$ & $1 / 1$ & 6.7 & 6.7 & 5.9 & 4.9 & 4.1 & 4.1 \\
\hline 550 & $2.8 \mathrm{e} 11$ & $6 \mathrm{D}$ & 0.0005 & 0.67 & $/ 0.68$ & $1 / 1$ & 6.1 & 6.1 & 5.5 & 4.5 & 4.1 & 4.1 \\
\hline 551 & $3.0 \mathrm{e} 11$ & $6 \mathrm{D}$ & 0.0005 & 0.67 & / 0.68 & $1 / 1$ & 6.1 & 6.1 & 4.7 & 5.1 & 3.8 & 3.8 \\
\hline
\end{tabular}

< With BBC, PI phasers, Q', correction >

\begin{tabular}{|c|c|c|c|c|c|c|c|c|c|c|c|c|}
\hline 552 & 1. $2 \mathrm{e} 11$ & $6 \mathrm{D}$ & 0.0003 & 0.67 & / 0.68 & $1 / 1$ & 6.5 & 6.1 & 5.3 & 5.7 & 6.1 & 5.3 \\
\hline 553 & $1.4 \mathrm{e} 11$ & $6 \mathrm{D}$ & 0.0003 & 0.67 & / 0.68 & $1 / 1$ & 6.5 & 6.3 & 5.9 & 5.9 & 6.3 & 5.9 \\
\hline 554 & $1.6 \mathrm{e} 11$ & $6 \mathrm{D}$ & 0.0003 & 0.67 & / 0.68 & $1 / 1$ & 6.9 & 6.5 & 5.9 & 6.1 & 6.3 & 5.9 \\
\hline 555 & $1.8 \mathrm{e} 11$ & $6 \mathrm{D}$ & 0.0003 & 0.67 & $/ 0.68$ & $1 / 1$ & 6.7 & 6.7 & 6.3 & 5.9 & 5.5 & 5.5 \\
\hline 556 & $2.0 \mathrm{e} 11$ & $6 \mathrm{D}$ & 0.0003 & 0.67 & / 0.68 & $1 / 1$ & 6.5 & 6.9 & 6.3 & 5.9 & 5.9 & 5.9 \\
\hline 557 & $2.2 \mathrm{e} 11$ & $6 \mathrm{D}$ & 0.0003 & 0.67 & / 0.68 & $1 / 1$ & 6.7 & 6.5 & 6.3 & 5.9 & 5.9 & 5.9 \\
\hline 558 & $2.4 \mathrm{e} 11$ & $6 \mathrm{D}$ & 0.0003 & 0.67 & / 0.68 & $1 / 1$ & 6.5 & 6.7 & 6.3 & 5.7 & 5.3 & 5.3 \\
\hline 559 & $2.6 \mathrm{e} 11$ & $6 \mathrm{D}$ & 0.0003 & 0.67 & $/ 0.68$ & $1 / 1$ & 6.3 & 6.5 & 6.3 & 5.9 & 5.7 & 5.7 \\
\hline 560 & $2.8 \mathrm{e} 11$ & $6 \mathrm{D}$ & 0.0003 & 0.67 & / 0.68 & $1 / 1$ & 6.3 & 6.5 & 5.9 & 5.3 & 6.3 & 5.3 \\
\hline 561 & $3.0 \mathrm{e} 11$ & $6 \mathrm{D}$ & 0.0003 & 0.67 & / 0.68 & $1 / 1$ & 6.1 & 6.3 & 5.9 & 4.7 & 4.1 & 4.1 \\
\hline 562 & 1. $2 \mathrm{e} 11$ & $6 \mathrm{D}$ & 0.0005 & 0.67 & / 0.68 & $1 / 1$ & 6.7 & 6.1 & 5.3 & 5.1 & 4.9 & 4.9 \\
\hline 563 & $1.4 \mathrm{e} 11$ & $6 \mathrm{D}$ & 0.0005 & 0.67 & / 0.68 & $1 / 1$ & 6.5 & 6.3 & 5.7 & 5.5 & 4.9 & 4.9 \\
\hline 564 & $1.6 e 11$ & $6 \mathrm{D}$ & 0.0005 & 0.67 & / 0.68 & $1 / 1$ & 6.7 & 6.5 & 5.9 & 5.5 & 5.1 & 5.1 \\
\hline 565 & $1.8 \mathrm{e} 11$ & $6 \mathrm{D}$ & 0.0005 & 0.67 & / 0.68 & $1 / 1$ & 6.7 & 6.7 & 6.1 & 5.9 & 5.5 & 5.5 \\
\hline 566 & $2.0 \mathrm{e} 11$ & $6 \mathrm{D}$ & 0.0005 & 0.67 & / 0.68 & $1 / 1$ & 6.7 & 6.3 & 5.9 & 5.5 & 5.3 & 5.3 \\
\hline 567 & $2.2 \mathrm{e} 11$ & $6 \mathrm{D}$ & 0.0005 & 0.67 & / 0.68 & $1 / 1$ & 6.5 & 6.9 & 6.3 & 5.7 & 5.5 & 5.5 \\
\hline 568 & $2.4 \mathrm{e} 11$ & $6 \mathrm{D}$ & 0.0005 & 0.67 & $/ 0.68$ & $1 / 1$ & 6.7 & 6.7 & 6.1 & 5.7 & 5.1 & 5.1 \\
\hline 569 & $2.6 e 11$ & $6 \mathrm{D}$ & 0.0005 & 0.67 & / 0.68 & $1 / 1$ & 6.3 & 6.5 & 5.9 & 6.3 & 4.5 & 4.5 \\
\hline 570 & $2.8 e 11$ & $6 \mathrm{D}$ & 0.0005 & 0.67 & $/ 0.68$ & $1 / 1$ & 5.9 & 7.1 & 6.3 & 4.7 & 4.1 & 4.1 \\
\hline 571 & $3.0 \mathrm{e} 11$ & $6 \mathrm{D}$ & 0.0005 & 0.67 & / 0.68 & $1 / 1$ & 6.3 & 5.9 & 5.9 & 4.7 & 4.1 & 4.1 \\
\hline
\end{tabular}

copy workshop508 to 572 , redo $\mathrm{Np}=2.5 \mathrm{e} 11 \mathrm{BB}$ only to check DA in 75 degree 


\section{Appendix II: DAs with 4-D beam-beam treatment}

Subject: Evaluation of dynamic aperture in presence of head-on beam-beam compensation in RHIC $\mathrm{BB}$ at IP6 and IP8: 4-D weak-strong

E-lens : 4-D weak-strong with zero length

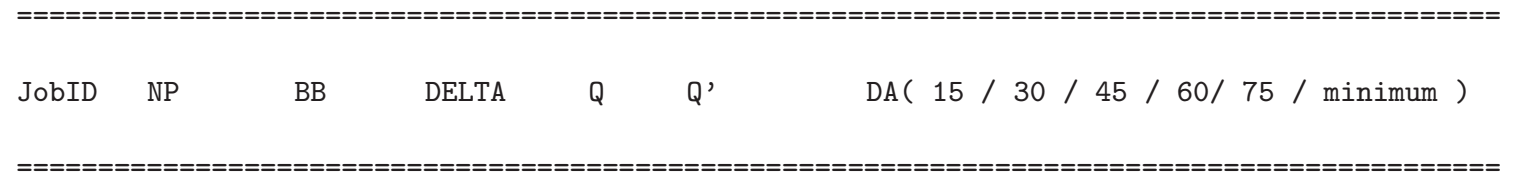

Only BB at IP6:

$\begin{array}{llllllllllll}89 & 2.0 \mathrm{e} 11 & 4 \mathrm{D} & 0.0 & .67 / .68 & 1 / 1 & 6.9 & 7.5 & 7.1 & 5.9 & 7.5 & 5.9 \\ 90 & 2.5 \mathrm{e} 11 & \text { 4D } & 0.0 & .67 / .68 & 1 / 1 & 6.7 & 6.5 & 6.5 & 6.3 & 7.1 & 6.3 \\ 91 & 3.0 \mathrm{e} 11 & \text { 4D } & 0.0 & .67 / .68 & 1 / 1 & 6.7 & 6.3 & 6.5 & 6.1 & 7.7 & 6.1 \\ & & & & & & & & & & & \\ 92 & 2.0 \mathrm{e} 11 & 4 \mathrm{D} & 0.0005 & .67 / .68 & 1 / 1 & 6.7 & 6.7 & 6.1 & 5.5 & 5.1 & 5.1 \\ 93 & 2.5 \mathrm{e} 11 & 4 \mathrm{D} & 0.0005 & .67 / .68 & 1 / 1 & 6.7 & 6.1 & 5.7 & 5.1 & 4.7 & 4.7 \\ 94 & 3.0 \mathrm{e} 11 & 4 \mathrm{D} & 0.0005 & .67 / .68 & 1 / 1 & 5.7 & 5.1 & 4.5 & 3.8 & 4.7 & 3.8\end{array}$

Only BB at IP6 and IP8:

$\begin{array}{rlllllllllll}95 & 2.0 \mathrm{e} 11 & \text { 4D } & 0.0 & .67 / .68 & 1 / 1 & 6.1 & 5.7 & 6.3 & 6.3 & 7.9 & 5.7 \\ 96 & 2.5 \mathrm{e} 11 & \text { 4D } & 0.0 & .67 / .68 & 1 / 1 & 7.9 & 6.3 & 6.3 & 6.9 & 7.3 & 6.3 \\ 97 & 3.0 \mathrm{e} 11 & \text { 4D } & 0.0 & .67 / .68 & 1 / 1 & 8.4 & 6.7 & 5.5 & 7.1 & 7.3 & 5.5 \\ & & & & & & & & & & & \\ 98 & 2.0 \mathrm{e} 11 & 4 \mathrm{D} & 0.0005 & .67 / .68 & 1 / 1 & 5.5 & 4.3 & 3.8 & 3.6 & 4.1 & 3.6 \\ 99 & 2.5 \mathrm{e} 11 & \text { 4D } & 0.0005 & .67 / .68 & 1 / 1 & 4.1 & 3.8 & 3.6 & 3.2 & 3.2 & 3.2 \\ 100 & 3.0 \mathrm{e} 11 & 4 \mathrm{D} & 0.0005 & .67 / .68 & 1 / 1 & 4.1 & 3.4 & 2.8 & 2.6 & 2.4 & 2.4\end{array}$

HBBC No phasers:

$\begin{array}{llllllllllll}51 & 2.0 \mathrm{e} 11 & \text { 4D } & 0.0 & .67 / .68 & 1 / 1 & 6.7 & 6.7 & 6.7 & 6.5 & 5.9 & 5.9 \\ 52 & 2.5 \mathrm{e} 11 & \text { 4D } & 0.0 & .67 / .68 & 1 / 1 & 6.5 & 6.5 & 5.7 & 4.9 & 6.3 & 4.9 \\ 53 & 3.0 \mathrm{e} 11 & \text { 4D } & 0.0 & .67 / .68 & 1 / 1 & 6.3 & 5.7 & 5.3 & 5.9 & 5.9 & 5.3 \\ & & & & & & & & & & & \\ 54 & 2.0 \mathrm{e} 11 & \text { 4D } & 0.0005 & .67 / .68 & 1 / 1 & 6.5 & 6.1 & 4.9 & 4.5 & 4.3 & 4.3 \\ 55 & 2.5 \mathrm{e} 11 & \text { 4D } & 0.0005 & .67 / .68 & 1 / 1 & 6.1 & 5.3 & 4.5 & 4.0 & 4.0 & 4.0 \\ 56 & 3.0 \mathrm{e} 11 & \text { 4D } & 0.0005 & .67 / .68 & 1 / 1 & 4.1 & 4.3 & 4.0 & 3.4 & 3.2 & 3.2\end{array}$

HBBC Added Phasers:

$\begin{array}{llllllllllll}57 & 2.0 \mathrm{e} 11 & 4 \mathrm{D} & 0.0 & .67 / .68 & 1 / 1 & 6.5 & 6.7 & 6.3 & 6.5 & 6.5 & 6.3 \\ 58 & 2.5 \mathrm{e} 11 & \text { 4D } & 0.0 & .67 / .68 & 1 / 1 & 6.1 & 6.1 & 6.3 & 5.7 & 6.5 & 5.7 \\ 59 & 3.0 \mathrm{e} 11 & 4 \mathrm{D} & 0.0 & .67 / .68 & 1 / 1 & 5.9 & 5.7 & 5.5 & 5.5 & 6.5 & 5.5 \\ & & & & & & & & & & & \\ 60 & 2.0 \mathrm{e} 11 & 4 \mathrm{D} & 0.0005 & .67 / .68 & 1 / 1 & 6.5 & 6.5 & 5.9 & 5.3 & 4.1 & 4.1 \\ 61 & 2.5 \mathrm{e} 11 & 4 \mathrm{D} & 0.0005 & .67 / .68 & 1 / 1 & 6.1 & 6.1 & 5.7 & 4.5 & 4.1 & 4.1 \\ 62 & 3.0 \mathrm{e} 11 & 4 \mathrm{D} & 0.0005 & .67 / .68 & 1 / 1 & 5.3 & 4.9 & 4.7 & 3.8 & 3.4 & 3.4\end{array}$

Scan deltap on top of phasers PI

$\begin{array}{llllllllllll}63 & 2.5 \mathrm{e} 11 & \text { 4D } & -0.0005 & .67 / .68 & 1 / 1 & 5.9 & 5.5 & 5.5 & 4.3 & 4.0 & 4.0 \\ 64 & 2.5 \mathrm{e} 11 & \text { 4D } & -0.0004 & .67 / .68 & 1 / 1 & 5.9 & 5.3 & 6.3 & 4.9 & 4.3 & 4.3 \\ 65 & 2.5 \mathrm{e} 11 & \text { 4D } & -0.0003 & .67 / .68 & 1 / 1 & 5.9 & 6.1 & 5.9 & 4.7 & 4.3 & 4.3 \\ 66 & 2.5 \mathrm{e} 11 & \text { 4D } & -0.0002 & .67 / .68 & 1 / 1 & 5.9 & 5.7 & 5.9 & 4.3 & 4.5 & 4.3 \\ 67 & 2.5 \mathrm{e} 11 & \text { 4D } & -0.0001 & .67 / .68 & 1 / 1 & 6.1 & 6.3 & 5.9 & 4.9 & 5.5 & 4.9\end{array}$




$\begin{array}{llllllllllll}68 & 2.5 \mathrm{e} 11 & 4 \mathrm{D} & 0.000 & .67 / .68 & 1 / 1 & 6.1 & 6.1 & 6.3 & 5.7 & 6.5 & 5.7 \\ 69 & 2.5 \mathrm{e} 11 & \text { 4D } & 0.0001 & .67 / .68 & 1 / 1 & 6.3 & 6.5 & 5.3 & 5.1 & 5.5 & 5.1 \\ 70 & 2.5 \mathrm{e} 11 & \text { 4D } & 0.0002 & .67 / .68 & 1 / 1 & 6.3 & 6.3 & 5.9 & 4.9 & 4.9 & 4.9 \\ 71 & 2.5 \mathrm{e} 11 & \text { 4D } & 0.0003 & .67 / .68 & 1 / 1 & 6.1 & 6.3 & 5.7 & 4.5 & 4.5 & 4.5 \\ 72 & 2.5 \mathrm{e} 11 & \text { 4D } & 0.0004 & .67 / .68 & 1 / 1 & 6.1 & 6.5 & 5.3 & 4.5 & 4.3 & 4.3 \\ 73 & 2.5 \mathrm{e} 11 & 4 \mathrm{D} & 0.0005 & .67 / .68 & 1 / 1 & 6.1 & 6.1 & 5.7 & 4.5 & 4.1 & 4.1\end{array}$

Scan $Q^{\prime}$ on top of phaser PI

$\begin{array}{llllllllllll}74 & 2.5 \mathrm{e} 11 & \text { 4D } & 0.0005 & 67 / .68 & -4 /-4 & 5.9 & 5.5 & 5.7 & 4.3 & 4.1 & 4.1 \\ 75 & 2.5 \mathrm{e} 11 & \text { 4D } & 0.0005 & .67 / .68 & -3 /-3 & 6.5 & 6.3 & 5.3 & 4.9 & 4.3 & 4.3 \\ 76 & 2.5 \mathrm{e} 11 & \text { 4D } & 0.0005 & .67 / .68 & -2 /-2 & 5.9 & 6.3 & 5.5 & 4.7 & 4.3 & 4.3 \\ 77 & 2.5 \mathrm{e} 11 & \text { 4D } & 0.0005 & .67 / .68 & -1 /-1 & 6.3 & 6.3 & 6.1 & 4.3 & 4.1 & 4.1 \\ 78 & 2.5 \mathrm{e} 11 & \text { 4D } & 0.0005 & .67 / .68 & 0 / 0 & 6.1 & 5.9 & 5.5 & 4.7 & 4.1 & 4.1 \\ 79 & 2.5 \mathrm{e} 11 & \text { 4D } & 0.0005 & .67 / .68 & 1 / 1 & 6.1 & 6.1 & 5.7 & 4.5 & 4.1 & 4.1 \\ 80 & 2.5 \mathrm{e} 11 & \text { 4D } & 0.0005 & .67 / .68 & 2 / 2 & 5.9 & 5.9 & 5.1 & 4.7 & 4.0 & 4.0 \\ 81 & 2.5 \mathrm{e} 11 & \text { 4D } & 0.0005 & 67 / .68 & 3 / 3 & 5.7 & 5.5 & 4.9 & 4.5 & 3.8 & 3.8 \\ 82 & 2.5 \mathrm{e} 11 & \text { 4D } & 0.0005 & 67 / .68 & 4 / 4 & 5.5 & 5.3 & 5.1 & 4.5 & 3.6 & 3.6\end{array}$

With $Q^{\prime}$ correction, $Q^{\prime}=1$, phasers PI etc.

$\begin{array}{lllllllllllll}83 & 2.0 \mathrm{e} 11 & 4 \mathrm{D} & 0.000 & 67 / .68 & 1 / 1 & 8.1 & 6.7 & 6.3 & 6.7 & 5.9 & 5.9 \\ 84 & 2.5 \mathrm{e} 11 & 4 \mathrm{D} & 0.000 & .67 / .68 & 1 / 1 & 6.1 & 6.5 & 5.9 & 5.7 & 6.3 & 5.7 \\ 85 & 3.0 \mathrm{e} 11 & 4 \mathrm{D} & 0.000 & .67 / .68 & 1 / 1 & 5.9 & 5.9 & 5.9 & 5.5 & 6.5 & 5.5 \\ & & & & & & & & & & & & \\ 86 & 2.0 \mathrm{e} 11 & 4 \mathrm{D} & 0.0005 & 67 / .68 & 1 / 1 & 6.5 & 6.5 & 6.1 & 5.3 & 4.7 & 4.7 \\ 87 & 2.5 \mathrm{e} 11 & 4 \mathrm{D} & 0.0005 & .67 / .68 & 1 / 1 & 6.3 & 5.9 & 5.3 & 4.9 & 4.3 & 4.3 \\ 88 & 3.0 \mathrm{e} 11 & 4 \mathrm{D} & 0.0005 & .67 / .68 & 1 / 1 & 5.3 & 5.3 & 4.5 & 4.0 & 3.8 & 3.8\end{array}$

on top of above, scan phasers away from PI

\begin{tabular}{|c|c|c|c|c|c|c|c|c|c|c|c|c|}
\hline & & & & & & Mfron & Ldeg. & & & & & \\
\hline 112 & $2.5 e 11$ & $4 \mathrm{D}$ & 0.0005 & $67 / .68$ & $1 / 1$ & $20+$ & 6.1 & 5.3 & 4.7 & 4.5 & 4.3 & 4.3 \\
\hline 113 & $2.5 \mathrm{e} 11$ & $4 \mathrm{D}$ & 0.0005 & $.67 / .68$ & $1 / 1$ & $15+$ & 5.9 & 5.3 & 4.9 & 4.5 & 4.3 & 4.3 \\
\hline 114 & $2.5 e 11$ & $4 \mathrm{D}$ & 0.0005 & $.67 / .68$ & $1 / 1$ & $10+$ & 5.7 & 6.1 & 5.5 & 4.7 & 4.1 & 4.1 \\
\hline 115 & $2.5 e 11$ & $4 \mathrm{D}$ & 0.0005 & $67 / .68$ & $1 / 1$ & $5+$ & 6.3 & 6.3 & 5.3 & 4.9 & 4.1 & 4.1 \\
\hline 116 & $2.5 \mathrm{e} 11$ & $4 \mathrm{D}$ & 0.0005 & $.67 / .68$ & $1 / 1$ & $2.5+$ & 6.1 & 6.1 & 5.7 & 4.7 & 4.1 & 4.1 \\
\hline 117 & $2.5 \mathrm{e} 11$ & $4 \mathrm{D}$ & 0.0005 & $.67 / .68$ & $1 / 1$ & 0 & 6.1 & 6.1 & 5.5 & 4.9 & 4.1 & 4.1 \\
\hline 118 & $2.5 e 11$ & $4 \mathrm{D}$ & 0.0005 & $67 / .68$ & $1 / 1$ & -2.5 & 6.1 & 6.3 & 5.5 & 4.7 & 4.3 & 4.3 \\
\hline 119 & $2.5 e 11$ & $4 \mathrm{D}$ & 0.0005 & $.67 / .68$ & $1 / 1$ & -5 & 6.1 & 6.3 & 5.9 & 4.7 & 4.5 & 4.5 \\
\hline 120 & $2.5 e 11$ & $4 \mathrm{D}$ & 0.0005 & $.67 / .68$ & $1 / 1$ & -10 & 6.1 & 5.7 & 5.3 & 4.5 & 4.5 & 4.5 \\
\hline 121 & $2.5 e 11$ & $4 \mathrm{D}$ & 0.0005 & $67 / .68$ & $1 / 1$ & -15 & 6.3 & 6.3 & 5.3 & 4.5 & 4.5 & 4.5 \\
\hline 122 & $2.5 \mathrm{e} 11$ & $4 \mathrm{D}$ & 0.0005 & $.67 / .68$ & $1 / 1$ & -20 & 6.1 & 6.3 & 5.3 & 4.5 & 4.5 & 4.5 \\
\hline 164 & $2.5 e 11$ & $4 \mathrm{D}$ & 0.0005 & $67 / .68$ & $1 / 1$ & $2.5+$ & 6.1 & 6.1 & 5.7 & 4.7 & 4.1 & 4.1 \\
\hline 165 & $2.5 e 11$ & $4 \mathrm{D}$ & 0.0005 & $.67 / .68$ & $1 / 1$ & $2.0+$ & 6.3 & 5.7 & 5.7 & 4.5 & 4.5 & 4.5 \\
\hline 166 & $2.5 e 11$ & $4 \mathrm{D}$ & 0.0005 & $.67 / .68$ & $1 / 1$ & $1.5+$ & 5.9 & 5.9 & 5.9 & 4.9 & 4.1 & 4.1 \\
\hline 167 & $2.5 \mathrm{e} 11$ & $4 \mathrm{D}$ & 0.0005 & $67 / .68$ & $1 / 1$ & 1.0 & 5.7 & 5.9 & 5.5 & 4.5 & 4.1 & 4.1 \\
\hline 168 & $2.5 e 11$ & $4 \mathrm{D}$ & 0.0005 & $.67 / .68$ & $1 / 1$ & $.5+$ & 6.1 & 6.1 & 6.1 & 4.5 & 4.3 & 4.3 \\
\hline 169 & $2.5 e 11$ & $4 \mathrm{D}$ & 0.0005 & $.67 / .68$ & $1 / 1$ & 0 & 6.1 & 6.1 & 5.5 & 4.9 & 4.1 & 4.1 \\
\hline 170 & $2.5 \mathrm{e} 11$ & $4 \mathrm{D}$ & 0.0005 & $67 / .68$ & $1 / 1$ & -0.5 & 6.5 & 6.3 & 5.7 & 4.9 & 4.9 & 4.9 \\
\hline 171 & $2.5 e 11$ & $4 \mathrm{D}$ & 0.0005 & $.67 / .68$ & $1 / 1$ & -1.0 & 6.1 & 6.5 & 5.7 & 4.5 & 4.3 & 4.3 \\
\hline 172 & $2.5 e 11$ & $4 \mathrm{D}$ & 0.0005 & $.67 / .68$ & $1 / 1$ & -1.5 & 5.9 & 6.1 & 5.5 & 4.7 & 4.3 & 4.3 \\
\hline 173 & $2.5 e 11$ & $4 \mathrm{D}$ & 0.0005 & $67 / .68$ & $1 / 1$ & -2.0 & 6.3 & 5.9 & 5.3 & 5.1 & 4.3 & 4.3 \\
\hline 174 & $2.5 \mathrm{e} 11$ & $4 \mathrm{D}$ & 0.0005 & $.67 / .68$ & $1 / 1$ & -2.5 & 6.1 & 6.3 & 5.5 & 4.7 & 4.3 & 4.3 \\
\hline
\end{tabular}

